OPEN ACCESS

Edited by: Alexandre Morrot, Federal University of Rio de Janeiro, Brazil

Reviewed by: Birgit Strobl,

University of Veterinary Medicine Vienna, Austria Celio Geraldo Freire De Lima, Federal University of Rio de Janeiro, Brazil

*Correspondence: Jason P. Gigley jgigley@uwyo.edu

Specialty section: This article was submitted to Microbial Immunology, a section of the journal

Frontiers in Immunology

Received: 17 June 2016

Accepted: 30 August 2016 Published: 23 September 2016

Citation:

Ivanova DL, Fatima R and Gigley JP (2016) Comparative Analysis of Conventional Natural Killer Cell Responses to Acute Infection with Toxoplasma gondii Strains of Different Virulence. Front. Immunol. 7:347. doi: 10.3389/fimmu.2016.00347

\section{Comparative Analysis of Conventional Natural Killer Cell Responses to Acute Infection with Toxoplasma gondii Strains of Different Virulence}

\author{
Daria L. Ivanova, Rida Fatima and Jason P. Gigley* \\ Department of Molecular Biology, University of Wyoming, Laramie, WY, USA
}

Conventional natural killer (cNK) cells, members of group 1 innate lymphoid cells, are a diverse cell subpopulation based on surface receptor expression, maturation, and functional potential. cNK cells are critical for early immunity to Toxoplasma gondii via IFN $\gamma$ production. Acute cNK cell responses to infection with different strains of $T$. gondii have not yet been characterized in detail. Here, we comprehensively performed this analysis with Type I virulent RH, Type II avirulent ME49, and fully attenuated Type I cps 1-1 strains. In response to these three parasite strains, murine cNK cells produce IFN $\gamma$ and become cytotoxic and polyfunctional (IFN $\gamma+\mathrm{CD} 107 \mathrm{a}+$ ) at the site of infection. In contrast to virulent $\mathrm{RH}$ and avirulent ME49 T. gondii strains, attenuated cps1-1 induced only local cNK cell responses. Infections with $\mathrm{RH}$ and ME49 parasites significantly decreased cNK cell frequency and numbers in spleen 5 days post infection compared with cps 1-1 parasites. cNK cell subsets expressing activating receptors Ly49H, Ly49D, and NKG2D and inhibitory receptors Ly49I and CD94/NKG2A were similar when compared between the strains and at 5 days post infection. cNK cells were not proliferating (Ki67-) 5 days post infection with any of the strains. cNK cell maturation as measured by CD27, CD11b, and KLRG1 was affected after infection with different parasite strains. $\mathrm{RH}$ and ME49 infection significantly reduced mature cNK cell frequency and increased immature cNK cell populations compared with cps1-1 infection. Interestingly, KLRG1 was highly expressed on immature cNK cells after $\mathrm{RH}$ infection. After $\mathrm{RH}$ and ME49 infections, CD69+ cNK cells in spleen were present at higher frequency than after cps 1-1 infection, which may correlate with loss of the mature cNK cell population. Cytokine multiplex analysis indicated cNK cell responses correlated with peritoneal exudate cell, spleen, and serum proinflammatory cytokine levels, including IL-12. qPCR analysis of parasite-specific B1 gene revealed that parasite burdens may affect cNK cell responses. This study demonstrates infection with $\mathrm{RH}$ and ME49 parasites impacts cNK cell maturation during acute $T$. gondii infection. Different $\mathrm{cNK}$ cell responses could impact early immunity and susceptibility to these strains.

Keywords: Toxoplasma gondii, toxoplasmosis, natural killer cells, virulence, cytokines 


\section{INTRODUCTION}

Toxoplasma gondii is a highly prevalent food-borne obligate intracellular parasitic protozoan present in 30\% of humans, which is a significant health concern as an opportunistic infection in immunocompromised people (1). Health outcomes after infection depend on many factors, including parasite genotype. In North America and Europe, T. gondii strains are represented by frequently found type II, III, 12 strains of a low virulence (LD50s of $\sim 10^{3}, 10^{5}, 10^{3}$ parasites, respectively) and less common but highly virulent type I strain (100\% lethal dose [LD100], 1 parasite) (2). Parasite virulence can affect how well the immune system responds, leading to differences in infection pathology (3). Thus, understanding how different parasite strains impact immune response is critical to improve therapies and vaccines to combat this infection.

Control of acute and chronic T. gondii infection is mediated by Th1 cell-mediated immunity (4). Conventional natural killer (cNK) cells are critical for innate immunity to T. gondii by producing IFN $\gamma(5,6)$. cNK cell IFN $\gamma$ production is dependent upon IL-12 (6). cNK cells have also been shown to have an important helper role in stimulating adaptive immunity to T. gondii. In CD4 T cell-deficient mice cNK cell IFN $\gamma$ can help induce CD8 T cell immunity to T. gondii (7). IFN $\gamma$ produced by cNK cells also promotes development of inflammatory dendritic cells, which, in turn, activates $\mathrm{T}$ cell responses (8). cNK cells also show cytotoxic activity in a response to $T$. gondii parasites and their subcellular components (9-11). However, the importance of cNK cell cytotoxicity during $T$. gondii infection is still not known (12).

Conventional natural killer cells are innate immune cells important for early control of cancer and infectious pathogens. They are members of the newly named group 1 ILC population and develop in the bone marrow from the common lymphoid progenitor (13). cNK cells provide protection by producing proinflammatory cytokine IFN $\gamma$ and cytolytic activity. The activation of $\mathrm{cNK}$ is dependent upon the signals generated by activating and inhibitory receptors $(14,15)$. Activating receptors include those that recognize specific ligands expressed on the surface of target cells, Ly49H, Ly49D, and NKG2D, as well as cytokine receptors for IL-12 and Type I IFNs. Inhibitory receptors recognize classical and non-classical MHC class I molecules that are also expressed on the surface of target cells and include Ly49I and NKG2A. Via these receptors, cNK cells are turned on to provide immunity in many disease situations.

Engagement of receptors by specific ligands impacts the fate and composition of responding cNK cells (16). For example, $\mathrm{Ly} 49 \mathrm{H}$ activating receptor expressing cNK cells specifically recognize $\mathrm{m} 157$ proteins on MCMV-infected cells and develop memory response to subsequent MCMV infections (17). In human studies, cNK cells that express NKG2C/CD94 heterodimer expand in a response to HCMV (18) and other viruses, such as HIV (19-21), Hantavirus (22), and Chikungunya virus (23). Whether a dominant cNK cell population is associated with T. gondii infection is not clear. Additionally it is not known whether cNK cell population composition is affected by the infection with different $T$. gondii strains.
The functional potential of cNK cells can be dependent on cNK cell maturation (24). cNK cells progress through a 4-stage developmental program defined by the expression of CD27 and CD11b (25). Highly mature cNK cells (CD27-CD11b+) acquire complete functional potential, are able to migrate, and lose their proliferative potential (24). cNK cell maturation can be affected by the signals received during infection (26). The maturation profile of cNK cells during T. gondii infection is not known and is important to define to gain a better understanding on how infection may impact $\mathrm{cNK}$ cell development.

The question of how different T. gondii strains can affect cNK cell biology has not been thoroughly addressed. In this study, we pursue this question and find that infection with virulent $\mathrm{RH}$ and avirulent ME49 parasites negatively impacts specific aspects of cNK cell responses to infection. Regardless of parasite strain and the parasite load, $\mathrm{cNK}$ cells increase in the site of infection. This increase corresponds with increase in $\mathrm{cNK}$ activation and function. The attenuated Type I strain cps1-1 stimulates only a localized cNK cell response compared with parental RH strain and Type II strain ME49. RH and ME49 infections significantly reduce splenic cNK cell numbers. Despite differences in the magnitude of cNK cell responses, cNK cells appear to respond in a global manner with no distinct subpopulation bearing specific receptors. Parasite virulence appears to have an impact on $\mathrm{cNK}$ cell maturation where highly virulent $\mathrm{RH}$ strain results in a significant loss in mature $(\mathrm{CD} 27-\mathrm{CD} 11 \mathrm{~b}+) \mathrm{cNK}$ cell populations at both the site of infection and in the spleen. Differences in cNK cell maturation may correlate with different cytokine profiles.

\section{MATERIALS AND METHODS}

\section{Mice}

Female 6- to 8-week-old C57BL/6J mice (Jackson Labs) were used for all experiments. Animals were housed in specific pathogen-free conditions at the University of Wyoming Animal Facility.

\section{Ethics Statement}

This study was carried out in strict accordance following the recommendations in the Guide for the Care and Use of Laboratory Animals of the National Institutes of Health. The protocol was approved by the Institutional Animal Care and Use Committee (IACUC) of the University of Wyoming (PHS/NIH/OLAW assurance number: A3216-01).

\section{T. gondii Parasites, Infections}

Tachyzoites (tach.) of RH and RH $\Delta c p s I I$ (cps1-1) strains (kindly provided by Dr. Bzik, Dartmouth College, NH, USA) were cultured by serial passage in human fetal lung fibroblast (MRC5) cell monolayers in complete DMEM (supplemented with $0.2 \mathrm{mM}$ uracil for cps1-1 strain). For mouse infections, parasites were purified by filtration through a 3.0- $\mu \mathrm{m}$ filter (Merck Millipore Ltd.) and washed with phosphate-buffered saline (PBS). Mice were infected intraperitoneally (i.p.) with $1 \times 10^{3} \mathrm{RH}$ tach. or $1 \times 10^{6}$ cps1-1 tach. The brains of the 5-week ME49-infected 
C57BL/6 mice were used as a source of ME49 cysts. Mice were infected i.p. with 10 ME49 cysts.

\section{Cell Surface and Intracellular Staining for Flow Cytometry}

Peritoneal exudate cells (PECs) were harvested by washing peritoneum with $7 \mathrm{ml}$ of ice cold PBS. Spleens were crushed through a $70-\mu \mathrm{m}$ tissue strainer (VWR) and red blood cells lysed with RBC lysis buffer (Sigma). Single-cell suspensions were then plated at $1-2 \times 10^{6}$ cells/well and stained for flow cytometry. For surface staining, cells were washed twice with $1 \times$ PBS and stained for viability in $1 \times$ PBS using Fixable Live/ Dead aqua dye (Invitrogen) for $30 \mathrm{~min}$. After washing with $1 \times$ PBS, surface staining was performed using antibodies diluted in stain wash buffer (SWB, 2\% FBS in $1 \times$ PBS and EDTA) for 25 min on ice. For functional assays, total PECs and splenocytes were plated in wells coated with anti-NK1.1 (PK136, BioXcell). Cells were stimulated for $4 \mathrm{~h}$ in the presence of $1 \times$ protein transport inhibitor cocktail containing Brefeldin A/Monensin (eBiosciences) and anti-CD107a. After live dead and surface staining, cells were fixed and permeabilized for $1 \mathrm{~h}$ on ice (BD bioscience, Fix/Perm solution) followed by intracellular staining in permeabilization wash buffer with anti-IFN $\gamma$ APC (eBiosciences) antibody. For proliferation assays, surface and intracellular staining was repeated as described above directly ex vivo without anti-NK1.1 restimulation and staining with antiKi67 APC (Biolegend) antibody. After washing with $1 \times$ PBS, cells were resuspended in $1 \times$ PBS and acquired using Guava easyCyte HT (Millipore). All samples were analyzed with FlowJo software (Tree Star).

\section{Antibodies}

The following antibodies were purchased from Biolegend: CD3 BV510, CD49b (DX5) APC-Cy7, NKp46 BV421, CD11b PE, Ly49D PE, Streptavidin BV650, CD27 biotin, KLRG1 BV605, KLRG1 PerCP/Cy5.5, CD69 PerCP/Cy5.5, and Ki67 APC. The following antibodies were purchased from eBioscience: CD107a PerCP-eFluor710, Ly49I PE, CD94 FITC, IFN $\gamma$ APC, and Ly49H PE-Cyanine7. The following antibodies were purchased from BD Biosciences: NKG2A/C/E BV605. The following antibodies were purchased from Miltenyl Biotec: NKG2D (CD314) biotin, Ly49D biotin, and Ly49D PerCP-Vio700. To determine viability Invitrogen Fixable live/dead Aqua stain was used.

\section{IFN $\gamma$ Production by Isolated cNK Cells}

Conventional natural killer cells were purified from the PECs and spleens harvested from 5-day-infected (cps1-1, RH, ME49) mice using EasySep Mouse NK cell isolation kit (STEMCELL Technologies). cNK cells were then plated at $0.2 \times 10^{6} \mathrm{cNK}$ cells in $0.2 \mathrm{ml}$ of complete DMEM (10\% FCS, penn/strep, amphotericin B) per well in polystyrene 96-well culture plate and cultured at $37^{\circ} \mathrm{C}$ for $24 \mathrm{~h}$. After incubation, the cells underwent three freeze/ thaw cycles and were then centrifuged at 14,000 rpm for $10 \mathrm{~min}$. Supernatant was collected and used to measure IFN $\gamma$ protein concentration by ELISA according to manufacturer's protocol (Biolegend).

\section{Multiplex Cytokine Assays IL-12, IFN $\gamma$, IL-1 $\beta$, IL-10, TNF $\alpha$, IL-17A, IL-2, IL-21, and IL-15}

Total PECs and splenocytes were obtained from 5-day-infected (cps1-1, RH, ME49) and control mice. Cells were plated at $2 \times 10^{6}$ PECs and $5 \times 10^{6}$ splenocytes per well in complete DMEM $(10 \%$ FCS, penn/strep, amphotericin B) in polystyrene culture plate and cultured at $37^{\circ} \mathrm{C}$ for $24 \mathrm{~h}$. After incubation, the cells underwent three freeze/thaw cycles and were then centrifuged at 14,000 rpm for $10 \mathrm{~min}$. Supernatant was collected and used for cytokine determination. To obtain serum, whole blood from uninfected and 5-day-infected mice was harvested and incubated for $30 \mathrm{~min}$ at RT then centrifuged for $10 \mathrm{~min}$ at $14000 \mathrm{rpm}$. Serum was removed and used in cytokine assays. Multiplex cytokine assay was performed using MILLIPLEX MAP Mouse TH17 Magnetic Bead Panel (EMD MILLIPORE), according to the manufacturer's instructions. Analysis was conducted in a Bio-plex MAGPIX multiplex reader. Mouse IL-12/23(p40) concentration was measured by ELISA according to manufacturer's protocol (Biolegend).

\section{Real-time PCR for Parasite Burden}

DNA was extracted from entire PECs and spleens harvested from infected mice using a Qiagen DNeasy Blood \& Tissue Kit (Qiagen Sciences). Parasite DNA from $600 \mathrm{ng}$ of PECs and $800 \mathrm{ng}$ of splenic tissue DNA was amplified using primers specific for the T. gondii B1 gene (forward primer GGAACTGCATCCGTTCATG and reverse primer TCTTTAAAGCGTTCGTGGTC) at $20 \mathrm{pmol}$ of each per reaction (Integrated DNA Technologies) by real-time fluorogenic PCR using SsoAdvanced ${ }^{\mathrm{TM}}$ Universal IT SYBR ${ }^{\circledR}$ Green SMx (BIO-RAD) on a CFX Connect ${ }^{\mathrm{TM}}$ Real-Time System cycler (BIO-RAD). Parasite equivalents were determined by extrapolation from a standard curve.

\section{Statistical Analysis}

Statistical analysis was performed using Prism 6.0f (GraphPad) or Microsoft Excel 2011. Significant differences were calculated using either unpaired Student's $t$-test or analysis of variance (ANOVA). Significance is denoted where $p<0.05$.

\section{RESULTS}

\section{cNK Cells Frequency and Absolute Cell Numbers}

Different T. gondii strains can have differential effects on the activation of innate immune responses (3). Comparative analysis of cNK cell response to different $T$. gondii strains has not been performed. Therefore, we tested whether $\mathrm{cNK}$ cell responses to acute T. gondii infection were different depending on parasite strain. Mice were infected with Type I highly virulent $\mathrm{RH}$, attenuated RH strain cps1-1, and Type II strain avirulent ME49, and cNK cell frequencies and numbers were measured at the site of infection (peritoneum, PEC) and spleen. Mice were harvested 5 days after i.p. infection, and cNK cells were enumerated. We chose day 5 as a time point because this is when we detect $\mathrm{cNK}$ cell responses after infection with all three parasite strains. In uninfected mice, cNK cells, identified as CD3-DX5+NKp46+, constituted on average 
$3.2 \pm 2.0 \%$ of live PEC. Infection with cps $1-1$ induced significant increase in cNK cell frequency $(18.5 \pm 2.9 \%)$ (Figure 1A). Five days post RH and ME49 infection, the frequency of cNK cells at the site of infection did not increase (Figure 1B). Absolute cNK cell numbers per PEC only increased after cps1-1 infection and not after RH and ME49 infections (Figure 1B). cNK cell frequencies and numbers in spleen were different as compared with PEC. We found significant decreases in cNK cell frequency and absolute cell number after infection with all three strains in spleen (Figure 1C).

\section{cNK Cell IFN $\gamma$ Production, Cytotoxicity, and Polyfunctionality}

Conventional natural killer cells provide protection against infection and cancer by producing IFN $\gamma$ and cytolytic activity (27). Polyfunctional responses of cNK cells ( 2 or more functions per cell) are a positive prognostic marker for outcomes associated with certain infections $(28,29)$. T cell-independent cNK-produced IFN $\gamma$ is critical for early control of infection $(5,30)$. The importance of cNK cytotoxicity is not well understood for T. gondii infection (10), and whether cNK cells develop a polyfunctional
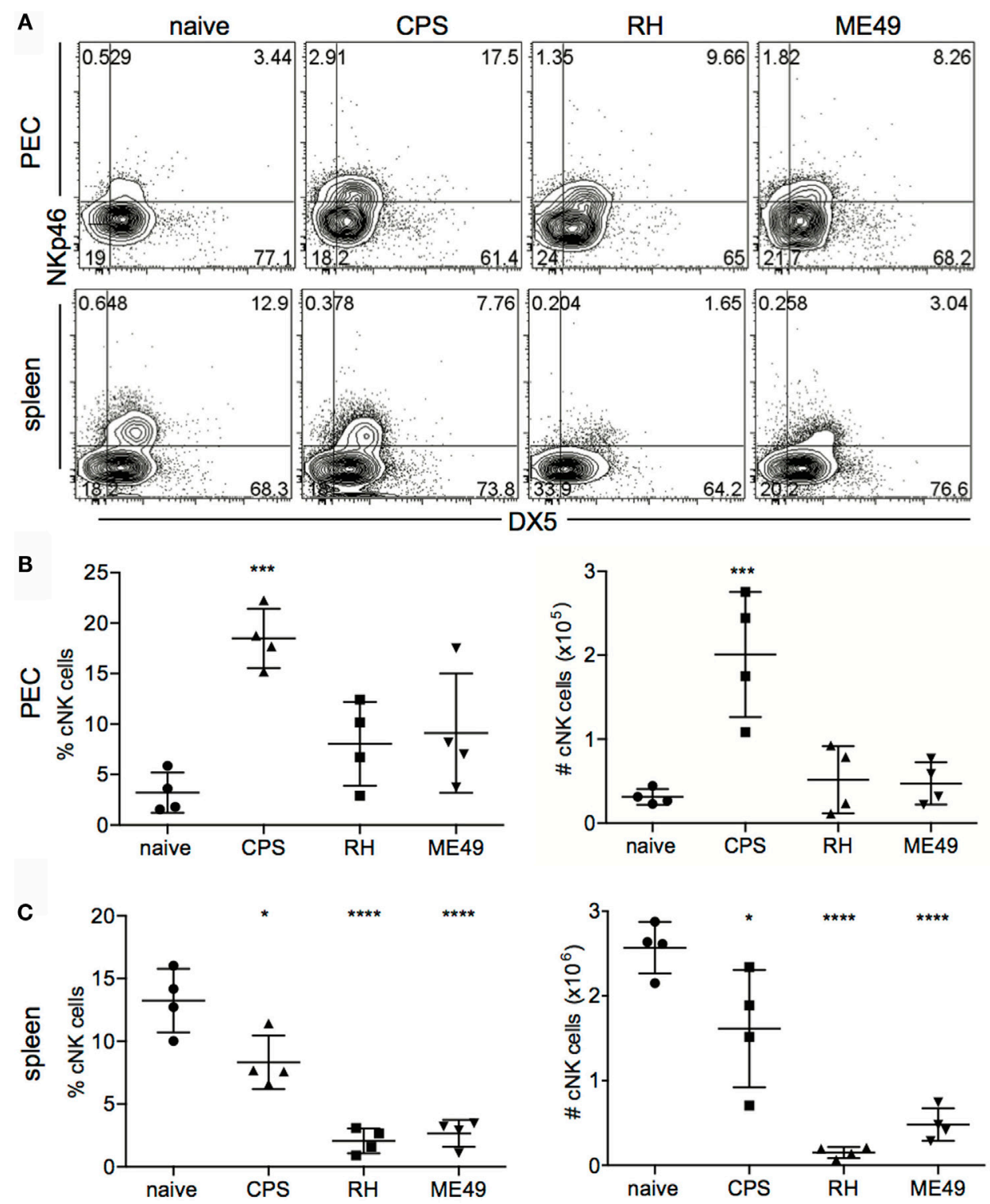

FIGURE 1 | cNK cell counts within mice peritoneal exudate cells and splenocytes after T. gondii infection. WT female C57BL/6 mice were infected i.p. with $1 \times 10^{6}$ cps 1-1, $1 \times 10^{3} \mathrm{RH}$ tachyzoites or 10 brain cysts of ME49. Five days after infection, peritoneal exudate cells (PECs) and splenocytes were harvested and stained for analysis by flow cytometry. (A) cNK cells were identified as CD3-DX5+NKp46+ cells. Representative contour plots of cNK cell frequency in PEC (upper row) and spleen (lower row). (B,C) Scatter plots present the mean \pm SD of cNK cell frequency (left graphs) and absolute cell number per organ (right graphs) calculated for individual mice in (B) PEC and (C) spleen. Data are representative of three experiments, $n=4$ per experiment. Statistical differences are represented by ${ }^{*} p<0.05,{ }^{* \star *} p<0.001$, and ${ }^{* \star * *} p<0.0001$ in comparison with the control group (naive). 
response to T. gondii is not known. Comparison of how different parasite strains impact $\mathrm{cNK}$ cell function has not been performed. Therefore, we measured $\mathrm{cNK}$ IFN $\gamma$, cytotoxicity as measured using the surrogate marker CD107 (31) and polyfunction $($ IFN $\gamma+\mathrm{CD} 107 \mathrm{a}+)$ after infection with three different strains of $T$. gondii infection to address these questions. The frequency of IFN $\gamma+\mathrm{cNK}$ cells in PEC increased after infections with all three strains (Figures 2A,B). However, the absolute number of IFN $\gamma+$ cNK cells per organ did not increase significantly after $\mathrm{RH}$ and ME49 infection (Figure 2B). Infection with the attenuated type I strain cps1-1 induced an increase in both frequency and absolute number of IFN $\gamma+c N K$ cells. In spleen, the frequency of IFN $\gamma$ producing $\mathrm{cNK}$ cells increased after $\mathrm{RH}$ and ME49 infections (Figures 2A,B). In contrast, attenuated cps1-1 parasites did not induce any increase in frequency of IFN $\gamma$-producing $\mathrm{cNK}$ cells in the spleen (Figures 2A,B). We did not detect an increase in absolute number in IFN $\gamma+\mathrm{cNK}$ cells in the spleen. Interestingly, $\mathrm{RH}$ infection resulted in a significant decrease in the absolute numbers of cNK cells capable of producing IFN $\gamma$ in the spleen (Figure 2B).

Previous studies demonstrate cNK cells can be cytotoxic against target cells stimulated with parasite components $(9,11)$.

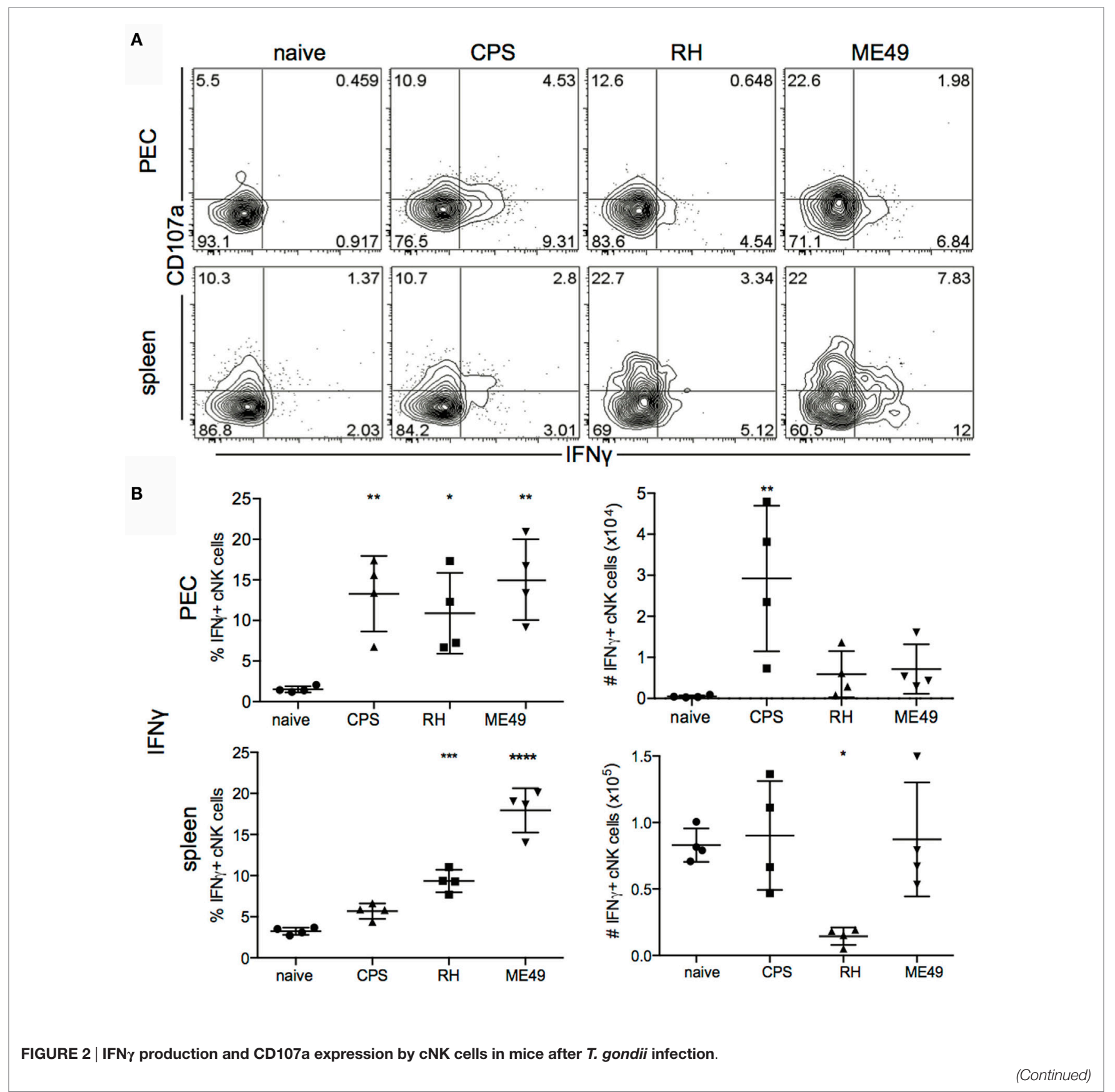



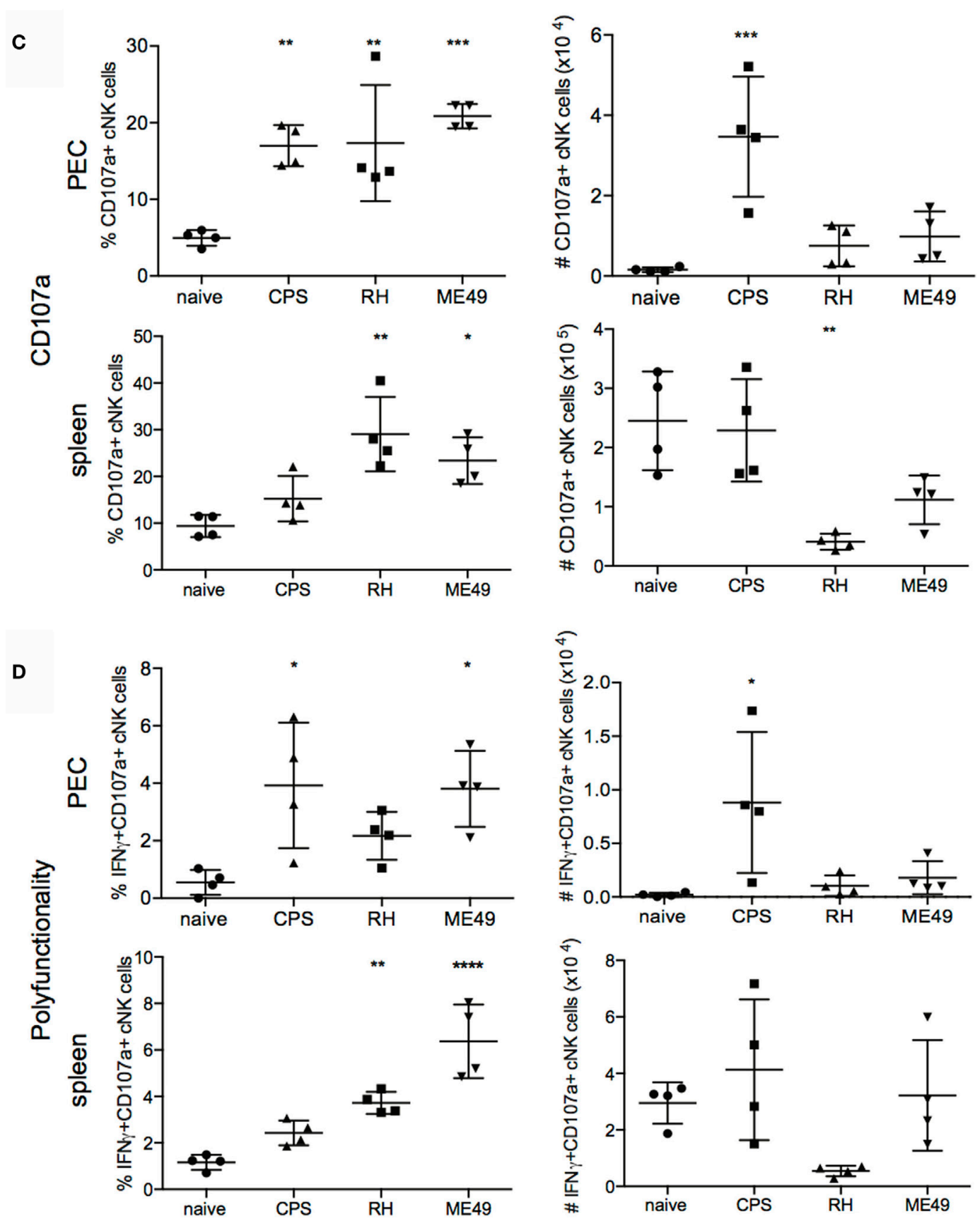

FIGURE 2 | Continued.

Functionality of cNK cells was measured in PECs and spleens harvested from uninfected and T. gondii-infected mice 5 days post infection and stimulated in vitro with plate bound anti-NK1.1 for $4 \mathrm{~h}$. Cells were stained for IFN $\gamma$ and cytolytic activity with anti-CD107a. (A) Contour plots representing frequency of IFN $\gamma+$,

CD107a+, and double positive polyfunctional IFN $\gamma+$ CD107a+ cNK cells in PEC (upper row) and spleen (lower row). (B) Scatter plots present frequency (left graphs) and number (right graphs) of IFN $\gamma+$ cNK cells in individual mice in PEC and spleen. (C) Scatter plots present frequency (left graphs) and number (right graphs) of cytotoxic CD107a+ cNK cells in individual mice in PEC and spleen. (D) Scatter plots present frequency (left graphs) and number (right graphs) of IFN $\gamma+$ CD107a+ cNK cells in individual mice in PEC and spleen. Data are representative of three experiments, $n=4$ per experiment. Individual values are mean \pm SD as shown. Statistical differences are represented by ${ }^{\star} p<0.05,{ }^{\star \star} p<0.01,{ }^{\star \star \star} p<0.001$, and ${ }^{\star \star \star \star} p<0.0001$ in comparison with the control group (naive).

The level of cNK cell cytolytic activity in response to different parasite strains has not been measured. We next assessed cNK cell cytotoxicity using CD107a (LAMP-1, the surrogate marker of cytotoxicity) expressed by cNK cells. The pattern of cytotoxic cNK cell response was similar to cNK cell IFN $\gamma$ response (Figure 2C). Cytotoxic CD107a + cNK cells increased in frequency in peritoneum after infections with all three strains and in spleen after RH and ME49 infections only (Figure 2C). Absolute numbers 
of cytotoxic cNK cells also followed a similar to IFN $\gamma$-producing cNK cells pattern. CD107a+cNK cells increased in number in the PEC after cps1-1 infection, but not after RH and ME49 infection. In the spleen, $\mathrm{RH}$ and ME49 infection stimulated an increase in CD107a + cNK cells. Interestingly, similar to IFN $\gamma+c N K$ cells, $\mathrm{RH}$ infection resulted in a significant decrease in CD107a+cNK cell numbers, while ME49 induced less of a decrease and cps1-1 infection did not alter cNK cytotoxic responses in the spleen (Figure 2C).

Polyfunctional cNK cell responses similar to polyfunctional $\mathrm{T}$ cell responses are an indicator of the quality and effectiveness of the immune response generated $(28,29)$. Whether $T$. gondii infection stimulates a polyfunctional $\mathrm{cNK}$ cell response is not well known. Polyfunctional responses of cNK cells were measured by cNK cells positive for both IFN $\gamma$ and CD107a. Polyfunctional cNK cells increased in frequency in the PEC after cps1-1 and ME49 infection (Figures 2A,D). RH infection did not stimulate a significant increase in polyfunctional $\mathrm{cNK}$ cell frequency in the PEC. Only infection with cps1-1 increased the absolute number of polyfunctional cNK cells in the PEC compared with RH and ME49 (Figure 2D). In the spleen only RH and ME49 infections resulted in increased polyfunctional $\mathrm{cNK}$ cell frequencies (Figure 2). However, the absolute number of polyfunctional cNK cells in spleen did not significantly change after all infections.

The cNK cell function assays above were carried out using plate bound anti-NK1.1 to restimulate the cells for flow cytometry. NK1.1 cross-linking with anti-NK1.1 can stimulate cNK cells from naive mice. Therefore, to verify whether there were differences in the level of IFN $\gamma$ produced by $\mathrm{cNK}$ cells at day 5 post infection with the different parasite strains, we purified $\mathrm{cNK}$ cells from infected animal PEC and spleen by negative selection. Normalized numbers of cNK cells from their respective tissue source were cultured, and IFN $\gamma$ was quantified in supernatants by ELISA. Peritoneal cNK cells from $\mathrm{RH}$-infected mice produced the highest quantity of IFN $\gamma$, followed by cNK cells from ME49infected mice and the lowest quantity of IFN $\gamma$ was produced by
cNK cells isolated from cps1-1-infected mice (Figure 3). Splenic cNK cells isolated from ME49- and $\mathrm{RH}$-infected mice produced IFN $\gamma$, but less than peritoneal cNK cells. As expected, splenic cNK cells from cps1-1 mice produced barely detectable amounts of IFN $\gamma$.

\section{Activating and Inhibitory Receptors Expression on cNK Cells}

Activating and inhibitory receptors tune how cNK cells respond to infection and are expressed in a stochastic array on cells (16). Stochastic expression can give rise to a bulk cNK population composed of many different subsets or subpopulations (16). There can be two phases of $\mathrm{cNK}$ cell responses, one that is cytokine dependent and the second being dependent upon engagement of activating receptor with cognate ligand (32, 33). MCMV infection is a good example of this biphasic response. cNK cells respond to Type I IFNs and IL-12 to initiate proliferative burst of cNK cells followed by selection of a specific cNK cell population where the viral protein $\mathrm{m} 157$ is recognized by the activating receptor $\mathrm{Ly} 49 \mathrm{H}$, thus promoting the survival and enrichment of this population $(33,34)$. Currently, whether a dominant $\mathrm{cNK}$ cell population arises to control T. gondii infection is not known. In addition, it is not clear how infections with different $T$. gondii strains change bulk cNK cell subpopulation composition based on activating and inhibitory receptor expression. Therefore, $\mathrm{cNK}$ cells were analyzed for expression of activating and inhibitory receptors in order to characterize changes in subpopulation composition after infection with three different $T$. gondii strains. Activating receptors (Ly49H, Ly49D, NKG2D) and inhibitory receptors (Ly49I, CD94/NKG2A) expressed by cNK cells in PEC and in spleen were measured 5 days after infection (Figure 4). In PEC, the frequency of activating receptor Ly49H and Ly49D expressing $\mathrm{cNK}$ cells increased after infection with cps 1-1, RH, and ME49 compared with naive controls (Figures 4A,D). The expression level of activating receptor NKG2D and the frequency of inhibitory receptor CD94/NKG2A cNK cells were reduced when
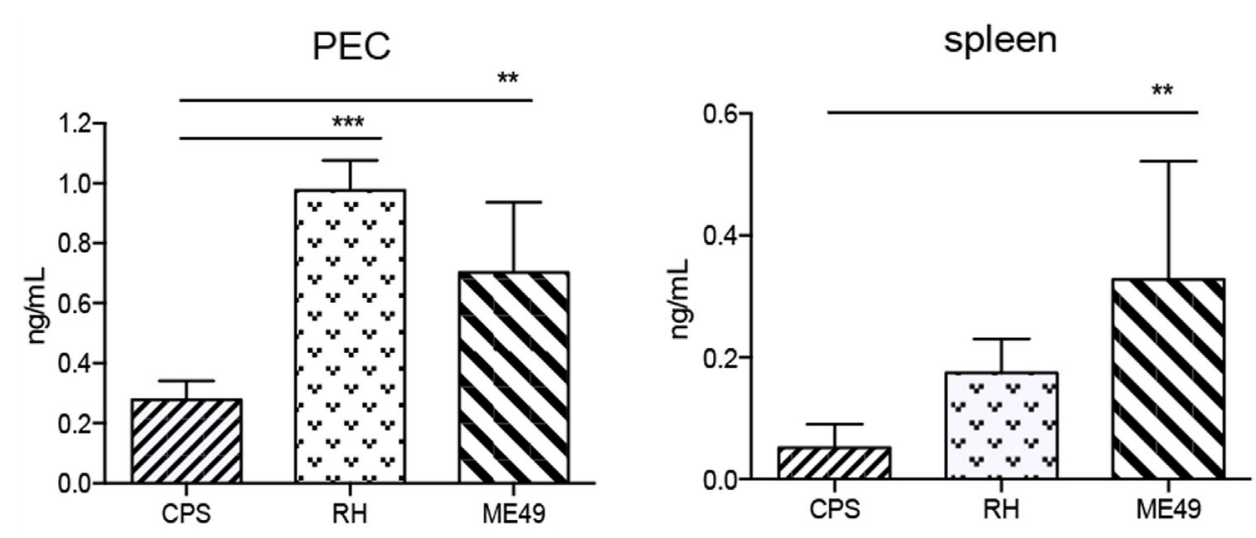

FIGURE 3 | Quantification of IFN $\gamma$ production by cNK cells in mice after $\mathbf{T}$. gondii infection. cNK cells were purified from PECs and spleens 5-dayT. gondii-infected mice and cultured for $24 \mathrm{~h}$ to measure IFN $\gamma$ protein in supernatants by ELISA. Bar graphs present concentration of IFN $\gamma$ protein in mice in PEC and spleen. Data are representative of two experiments, $n=4$ per experiment. Individual values shown are mean \pm SD. Statistical differences are represented by ${ }^{\star} p<0.05$, and ${ }^{* *} p<0.01$. 
A
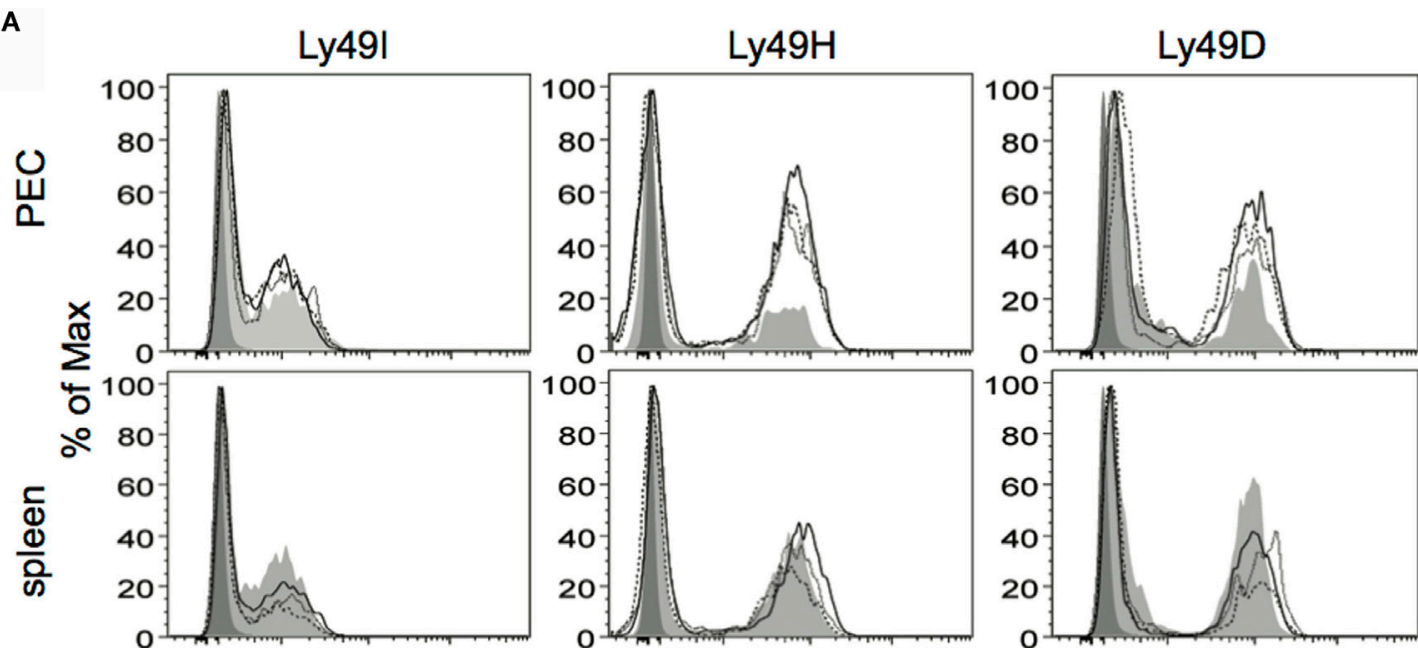

B

NKG2D
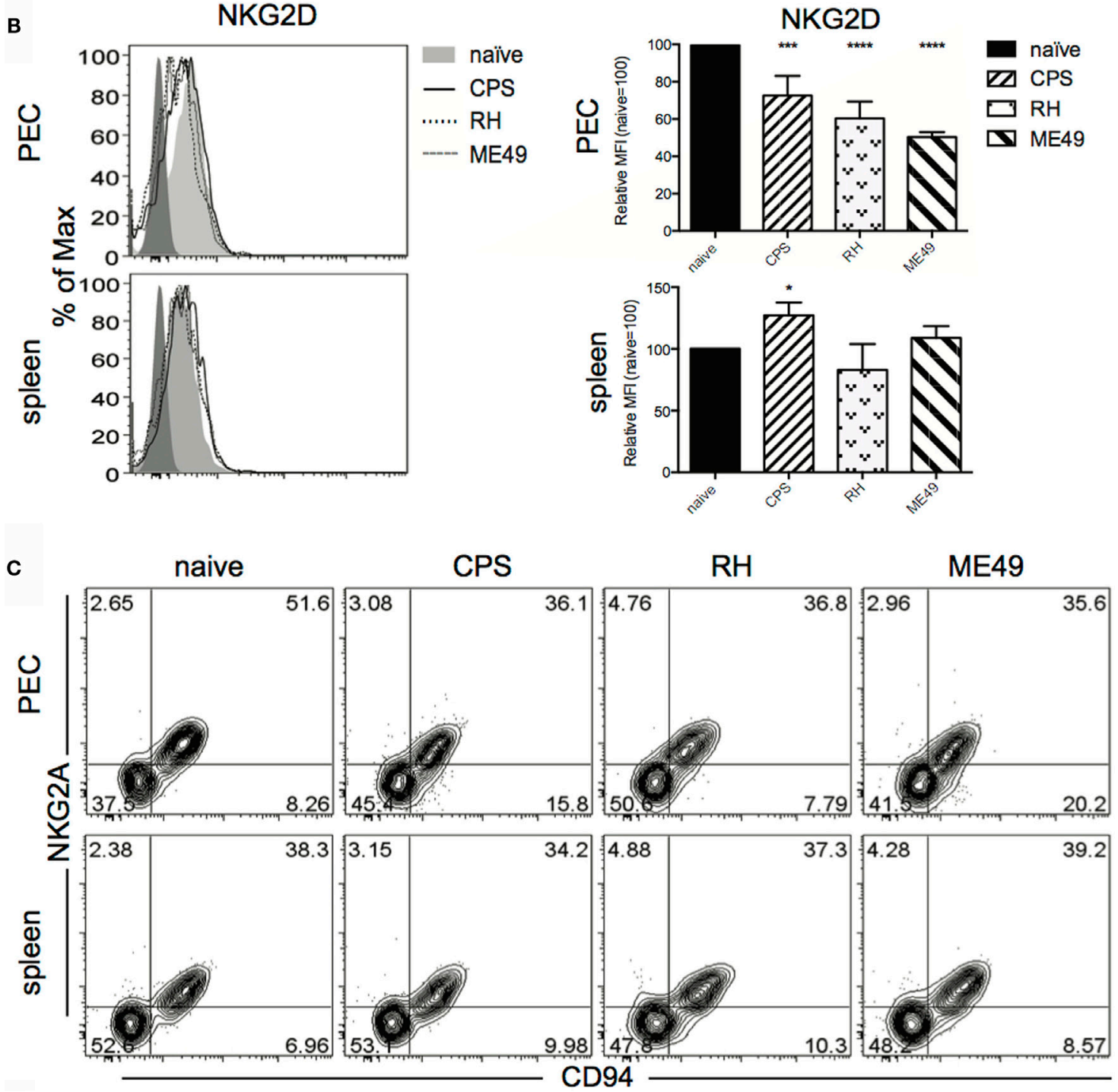

FIGURE 4 | Activating and inhibitory receptor expression by cNK cells within mice peritoneal exudate cells and splenocytes after $T$. gondii infection. 

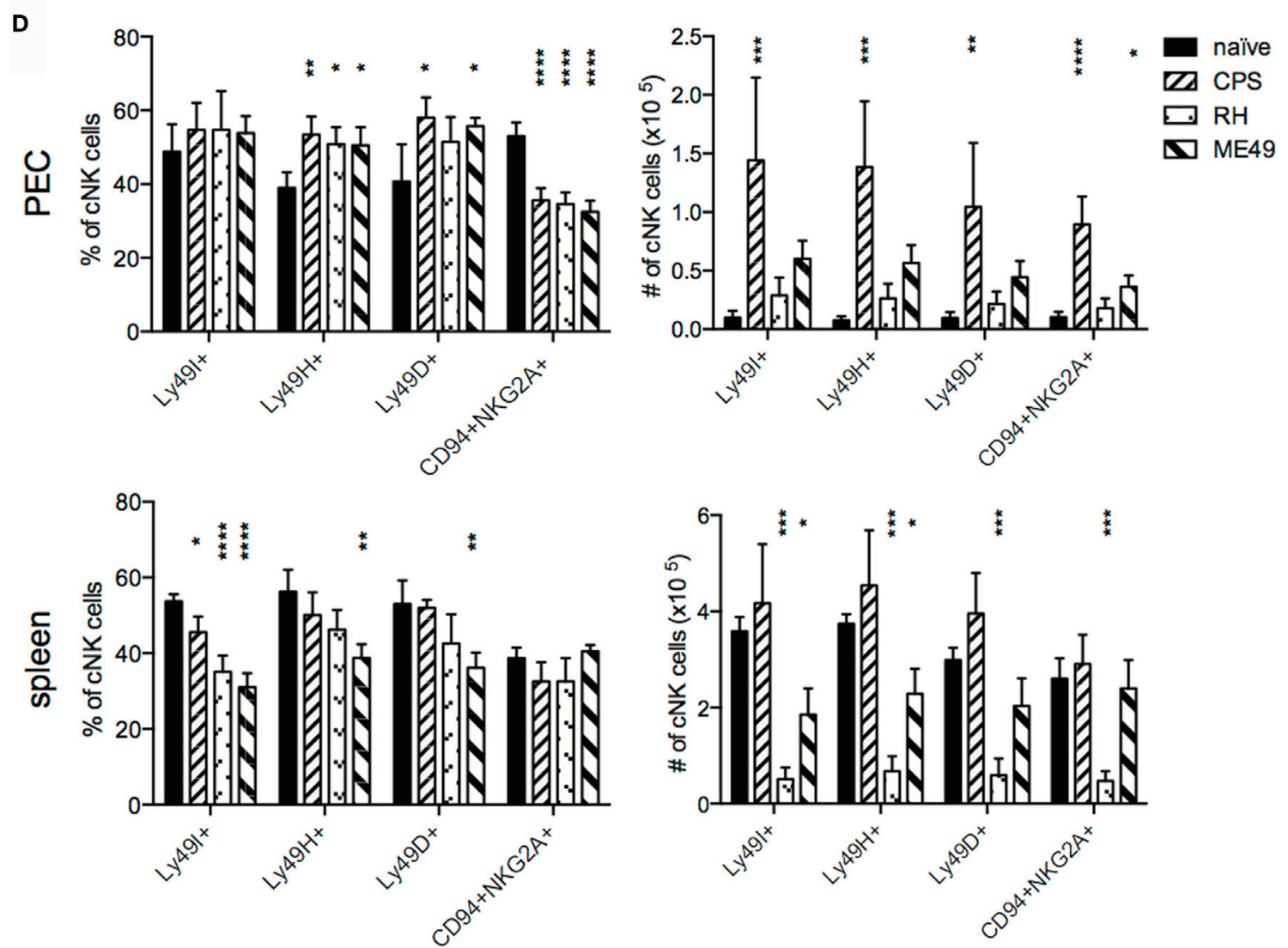

FIGURE 4 | Continued.

PECs and splenocytes isolated from uninfected and 5 day-T. gondii-infected mice were stained for analysis by flow cytometry for Ly49I, Ly49H, Ly49D, NKG2D, NKG2A, and CD94 expression on cNK cells (CD3-DX5+NKp46+). (A) Histograms present frequency of receptor positive and expression levels of Ly49I, Ly49H, and Ly49D on cNK cells in PEC and spleen. (B) Histograms present frequency of receptor positive and expression levels of NKG2D on cNK cells in PEC and spleen. Bar graphs present relative mean fluorescence intensity of NKG2D levels on cNK cells in PEC and spleen. (C) Representative contour plots of cNK cells gated for CD94/NKG2A expression in PEC and spleen. (D) Scatter plots present frequency and number of Ly491+, Ly49H+, Ly49D+, and CD94+NKG2A+ NK cells in individual mice in PEC and spleen. Data are representative of three experiments, $n=4$ per experiment. Individual values are mean \pm SD as shown. Statistical differences are represented by ${ }^{\star} p<0.05,{ }^{* \star} p<0.01,{ }^{* \star *} p<0.001$, and ${ }^{\star \star * \star} p<0.0001$ in comparison with the control group (naive).

compared with naive controls after infection with each strain of the parasite (Figures 4B-D). Inhibitory receptor Ly49I expressing cNK cells did not change in frequency. Absolute numbers in PEC revealed that among all three strains, $c p s 1-1$ infection stimulated the greatest increase in $\mathrm{cNK}$ subsets expressing activating receptors Ly49H and Ly49D, as wells as inhibitory receptors Ly49I and CD94/NKG2A (Figure 4D). The fold increase in absolute number of Ly49I+, Ly49H+, Ly49D+ cNK cells was greater than in CD94+ NKG2A+ cNK cells. In spleen, the most significant difference was a reduction in frequency and absolute number of cNK cells in a graded manner with increasing virulence of the strain (Figure 4D). Infection with cps1-1 did not stimulate a significant change in cNK cell subpopulation composition in the spleen (Figure 4D).

\section{The Phenotype of IFN $\gamma$-Producing cNK Cells}

Measuring changes in cNK cell subpopulations by activating or inhibitory receptor expression may not provide enough resolution to identify dominant cell populations responding to infection as shown in Figure 4. To better assess cNK cell subpopulation profiles, we analyzed IFN $\gamma+\mathrm{cNK}$ cells for receptor expression. cNK cells were stimulated ex vivo after 5 days of infection with anti-NK1.1 and stained intracellularly for IFN $\gamma$ production. $\mathrm{cNK}$ cells were surface stained for activating (Ly49H and Ly49D) and inhibitory (Ly49I and CD94/NKG2A) receptors and analysis was performed on IFN $\gamma+\mathrm{cNK}$ cells. In PEC, the numbers of IFN $\gamma+$ cNK cells expressing inhibitory receptors Ly49I or CD94/NKG2A and activating receptors Ly49H, Ly49D increased significantly after cps1-1 infection and not significantly after RH and ME49 infections (Figure 5A). In spleen, cps1-1 and ME49 infection had little impact on the receptor phenotype of IFN $\gamma+\mathrm{cNK}$ cells. After $\mathrm{RH}$ infection, there was a reduction in absolute numbers of IFN $\gamma+$ cNK cells positive for each receptor (Figure 5B).

\section{cNK Cell Maturation}

Conventional natural killer cells function during infection can be dependent on cNK cell maturation (26). cNK cells move 


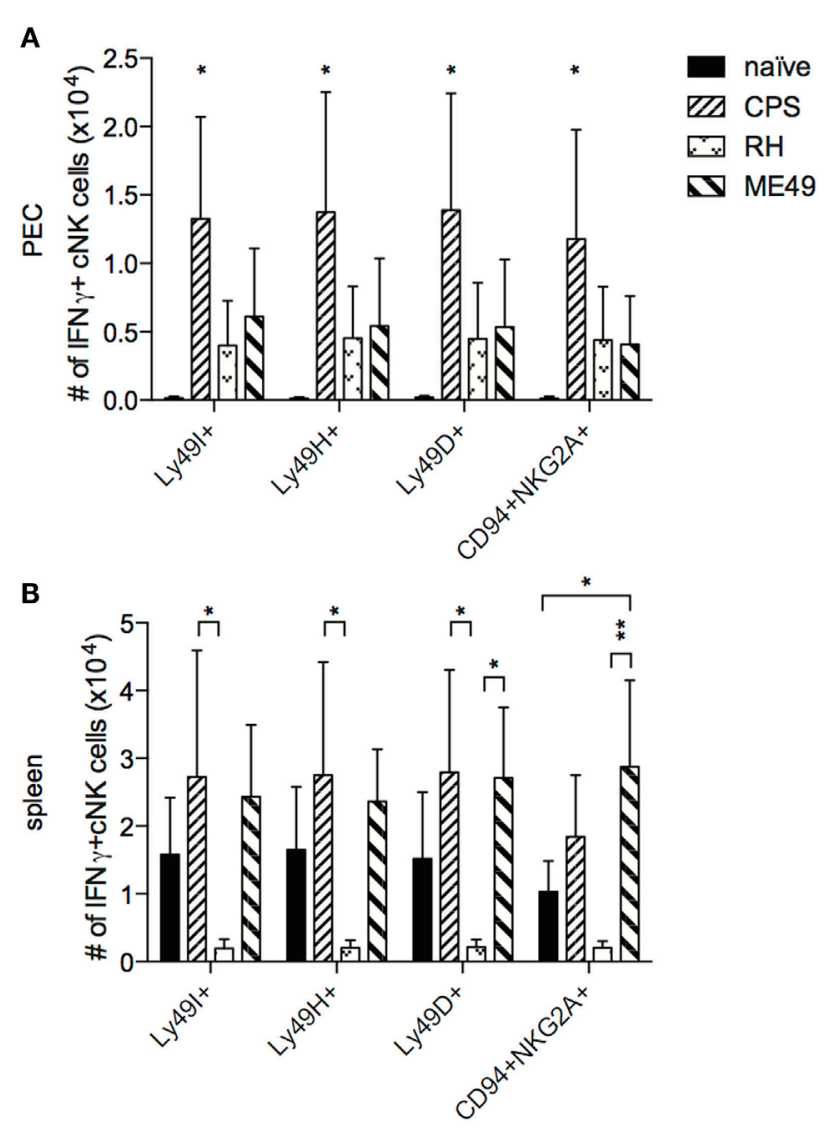

FIGURE 5 | IFN $\gamma$ production by distinct populations of cNK cells after T. gondii infection. PECs and splenocytes from uninfected and infected mice were restimulated in vitro with plate bound anti-NK1.1 for $4 \mathrm{~h}$, then stained for surface receptors, fixed, and subsequently stained for intracellular IFN $\gamma$. (A,B) CNK cells that were IFN $\gamma$ + were then gated for $\mathrm{cNK}$ cell receptors Ly49I, Ly49H, Ly49D, and CD94/NKG2A. Bar graphs present absolute cell number of each population per (A) PEC and (B) spleen. Data are representative of three experiments, $n=4$ per experiment. Individual values are mean $\pm \mathrm{SD}$ as shown. Statistical differences are represented by ${ }^{*} p<0.05$ and ${ }^{* *} p<0.01$, in comparison with the control naive group (A) and CPS or ME49 group (B).

through four distinct maturation steps marked by changes in expression of $\mathrm{CD} 27$ and $\mathrm{CD} 11 \mathrm{~b}(24,25)$. Stage 1 immature $\mathrm{cNK}$ cells are $\mathrm{CD} 27-\mathrm{CD} 11 \mathrm{~b}-$, followed by stage $2 \mathrm{CD} 27+\mathrm{CD} 11 \mathrm{~b}-$, stage 3 moderately mature $\mathrm{CD} 27+\mathrm{CD} 11 \mathrm{~b}+$ and stage 4 highly mature CD27-CD11b+ (25). Fully mature cNK cells acquire full functional competence, express a full complement of activating and inhibitory receptors, reduce their proliferative potential, and increase their migratory capacity (24). The cNK cell maturation profile and its correlation with activation and function during T. gondii infection are unknown. cNK maturation was measured 5 days after infection with cps1-1, RH, and ME49. As shown in Figure 6, cNK cell maturation status was determined based on expression of $\mathrm{CD} 27$ and $\mathrm{CD} 11 \mathrm{~b}$ as $\mathrm{R} 0(\mathrm{CD} 27-\mathrm{CD} 11 \mathrm{~b}-)$, R1 (CD27+CD11b-), R2 (CD27+CD11b+), and R3 (CD27+ $\mathrm{CD} 11 \mathrm{~b}+$ ). In naive mice, the majority of cNK cells were represented by $\mathrm{R} 2$ subpopulation in peritoneum and $\mathrm{R} 3$ in spleen (Figure 6). Infection with cps1-1 and ME49 parasites resulted in increased mature cNK cells in the PEC compared with naive controls (Figures 6A,B). The frequency and number of mature (R3) cNK cells in the PEC of RH-infected animals was significantly decreased compared with cps1-1 and ME49 (Figures 6A,B). RH infection appeared to stimulate a significant increase in frequency and absolute number of R0 and R1 immature cNK cells (Figures 6A,B). R0 immature cNK cells also were increased after ME49 infection, but not to the extent of $\mathrm{RH}$-infected animals in the PEC (Figures 6A,B). The pattern was different in the spleen. Infection with either of three parasite strains, in particular with ME49, induced increase in $\mathrm{R} 0$ and $\mathrm{R} 1 \mathrm{cNK}$ cells in spleen. R2 subpopulation in the spleen (Figures 6A,C) was enriched in frequency after RH infection. Interestingly, unlike after cps1-1 infection, highly mature R3 cNK cells were decreased after both RH and ME49 infections in spleen (Figures 6A,C).

Mature and activated cNK cells upregulate their KLRG1 expression, and KLRG1 is considered to be a marker of terminal maturation (35). The frequencies of KLRG1+ cNK cells increased in both site of infection and in the periphery in a response to all infections (Figures 6D,E). The absolute numbers of KLRG1+ cNK cells in PEC increased in response to cps1-1, but not to RH and ME49 infection. Absolute numbers of KLRG1+ cNK cells increased in spleen after cps1-1 and ME49 infection compared with $\mathrm{RH}$, where numbers were comparable to naive controls (Figure 6E).

Since we observed the increase in the immature CD11bcNK cell subsets and, simultaneously, an increase in highly mature KLRG1+ cNK cells after RH and ME49 infections, we, next, assessed the distribution of KLRG1+ cNK cells between CD11b- (R0, R1) and CD11b+ (R2, R3) subsets. We found in cps1-1-infected mice, KLRG1+ cNK cells had an expected distribution within mature $\mathrm{CD} 11 \mathrm{~b}+$ subsets, similarly to uninfected mice (Figures 6F-H). Unlike cps1-1 infection, after RH and ME49 infection, KLRG1 on cNK cells was more widely expressed across all maturation subsets. KLRG1 was highly expressed by immature CD11b- subsets and, in particular, within R1 compartment in PEC after RH infection and within R0 and R1 in spleen after ME49 infection.

\section{cNK Cell Activation and Proliferation after T. gondii Infection}

CD69 is upregulated on activated cNK cells and is an indicator of their migratory capacity $(36,37)$. CD69 expression has also been shown to have a regulatory function for $\mathrm{cNK}$ cells $(38,39)$. To further define how cNK cells respond to $T$. gondii infection and to compare how different parasite strains affect $\mathrm{cNK}$ cell activation and migration, we measured CD69 expression on cNK cells directly ex vivo without restimulation. The expression of CD69 (Figures 7A,B) correlated well with cNK cell function and maturation (Figures 2 and $\mathbf{6}$ ). The frequency of CD69+ cNK cells was increased after infection with all the strains in PEC and after RH and ME49 infections in spleen (Figures 7A,B). Absolute numbers of CD69+ cNK were increased in the PEC only after cps1-1 infection and not after RH or ME49. Absolute numbers 


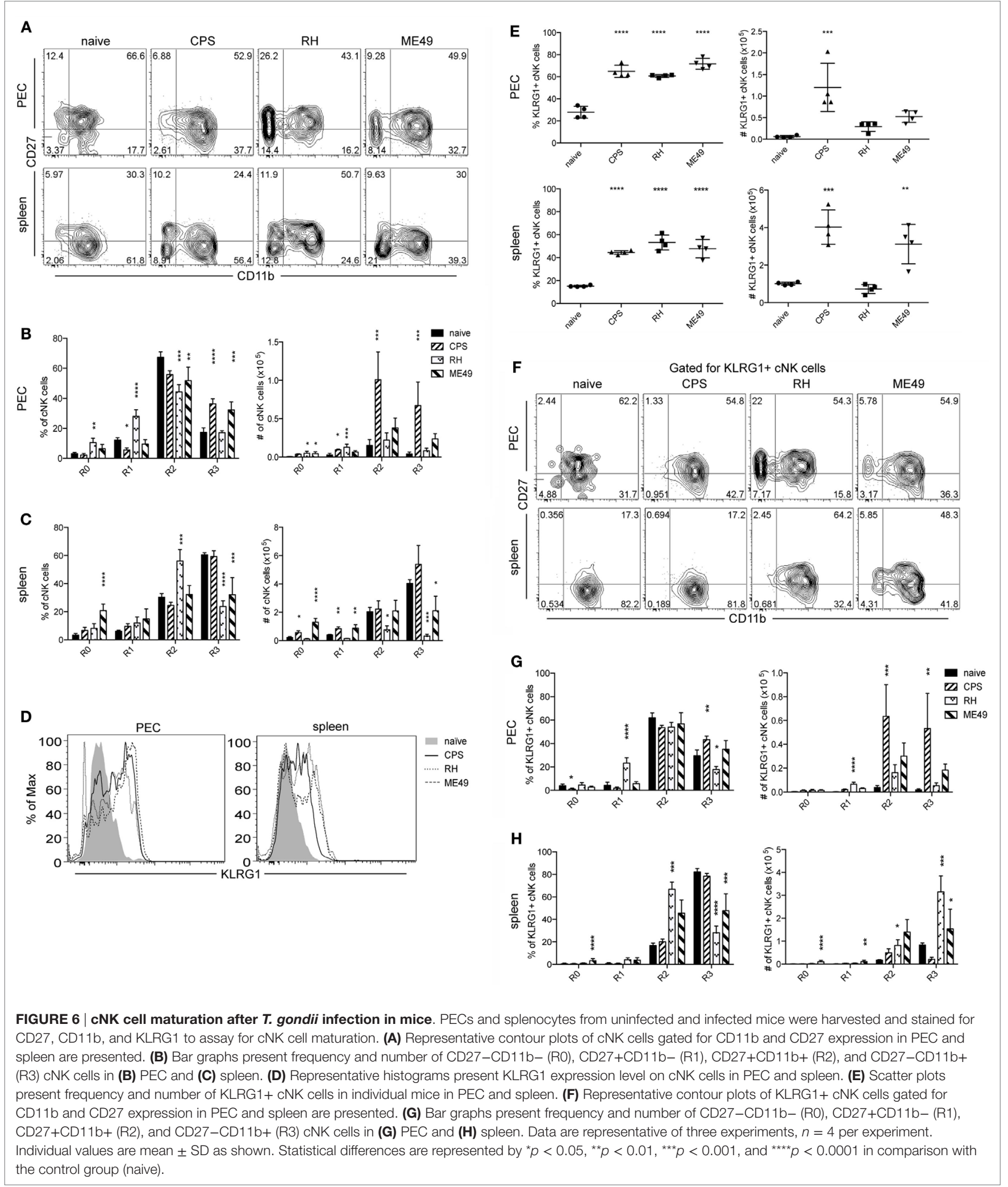


of CD69+ cNK cells in the spleen did not change after infection with all three strains.

Conventional natural killer cell proliferation was measured after T. gondii infection by intracellular staining for nuclear Ki67, a marker of cell cycle progression and a surrogate marker of cellular proliferation $(40,41)$. cNK cells did not appear to undergo proliferation at 5 days post infection in the PEC or spleen with any of the parasite strains tested (Figures 7C,D). Proliferative burst of cNK cells may occur earlier than 5 days post infection.

\section{The Levels of Cytokines in Mice \\ Peritoneum, Spleen and Plasma}

The activation of cNK cells is highly dependent upon the inflammatory cytokine milieu present during infection and specifically upon IL-12 $(6,42)$. The virulence of T. gondii strain types is associated with their ability to induce quantitatively and qualitatively different cytokine production (3). How the cytokine milieu correlates with cNK cell responses to infection with different $T$. gondii strains is not known. To address this question, the concentration of proinflammatory and immunoregulatory cytokines produced

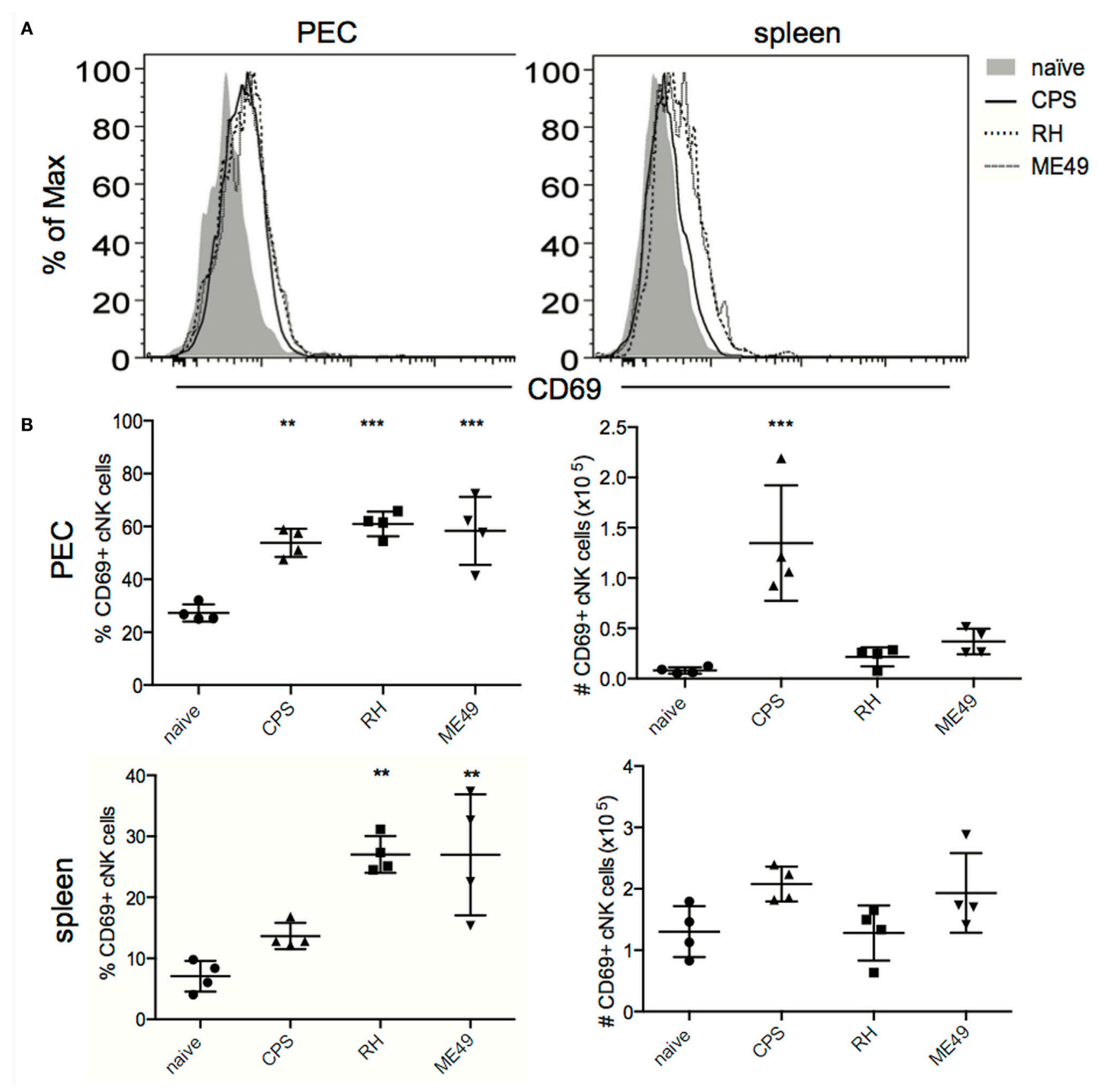

FIGURE 7 | cNK cell activation and proliferation after T. gondii infection 

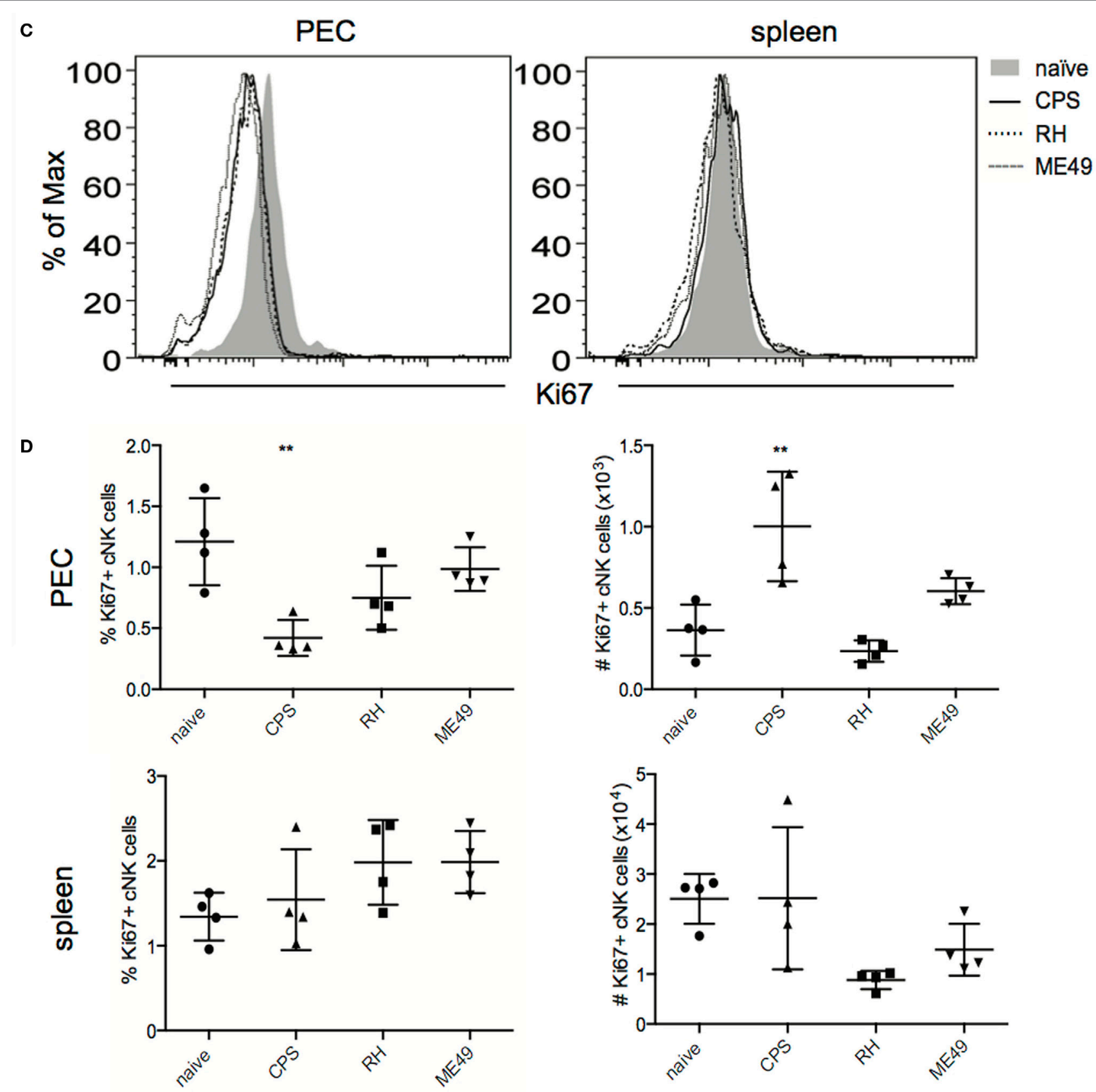

FIGURE 7 | Continued.

cNK cell activation was measured by staining for CD69 expression on cNK cells (CD3-DX5+NKp46+) directly ex vivo. Proliferation of cNK cells was measured by intracellular staining for Ki67 directly ex vivo. (A) Representative histograms present CD69 expression level on cNK cell in PEC and spleen. (B) Scatter plots present frequency and number of CD69+ cNK cells in individual mice in PEC and spleen. (C) Representative histograms present Ki67 expression level in cNK cells in PEC and spleen. (D) Scatter plots present frequency and number of Ki67+ cNK cells in individual mice in PEC and spleen. Data are representative of three experiments, $n=4$ per experiment. Individual values are mean \pm SD as shown. Statistical differences are represented by ${ }^{\star} p<0.05,{ }^{* \star} p<0.01,{ }^{{ }^{* \star \star}} p<0.001$, and ${ }^{{ }^{\star \star \star \star}} p<0.0001$ in comparison with the control group (naive).

at the site of infection, in spleen and serum, were tested using a multiplex approach (43). Additionally, ELISA analysis was performed to measure IL-12p40 at these different sites. Compared with naive animals, the level of IFN $\gamma$, IL-1 $\beta$, IL-17A, and IL-12 was increased at 5 days post infection in PEC (Figure 8). The level of immunoregulatory cytokine IL-10 was decreased in PEC after infections with all three strains (Figure 8A). The concentrations of all cytokines in spleen were lower than at the site of infection. The level of IFN $\gamma$ was similar after all infections (Figure 8); IL-1 $\beta$ was the highest in PEC after cps1-1 and in spleen after ME49; 
IL-17A was increased after cps1-1 and ME49 in PEC; IL-10 was increased after $\mathrm{RH}$ and ME49 in spleen. The concentrations of IL-2, IL-15, and IL-21 were beyond detection minimum (data not shown). ELISA for IL-12p40 indicated that RH infection induced the highest increase in production of this cytokine in PEC, spleen, and serum (Figure 8B). Infection with ME49 strain
A

PEC

IFN $\gamma$

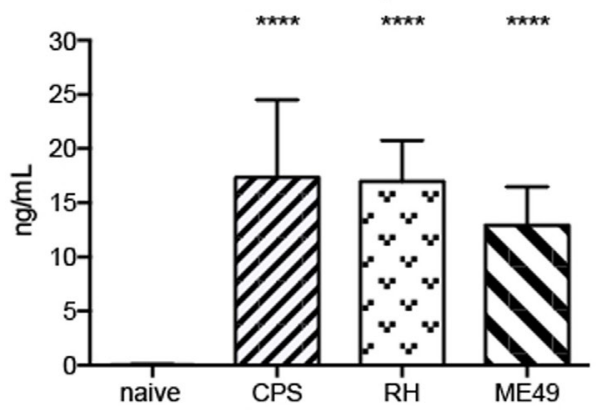

IL-1 $\beta$
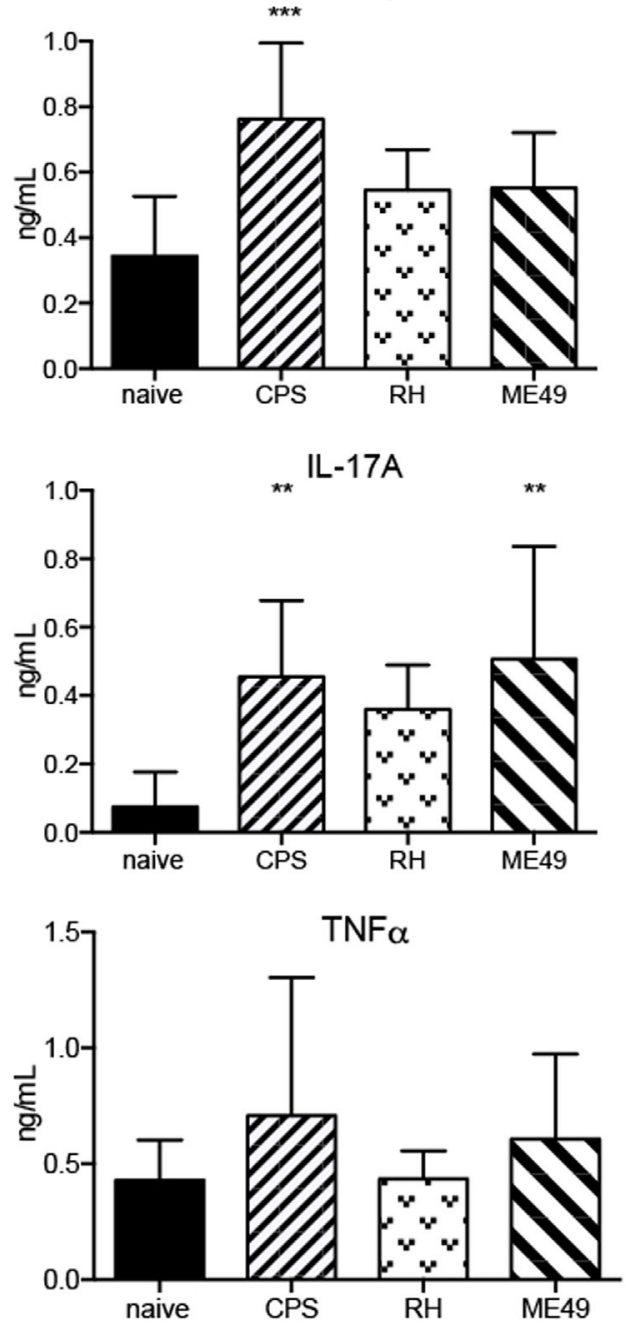

spleen

IFN $\gamma$

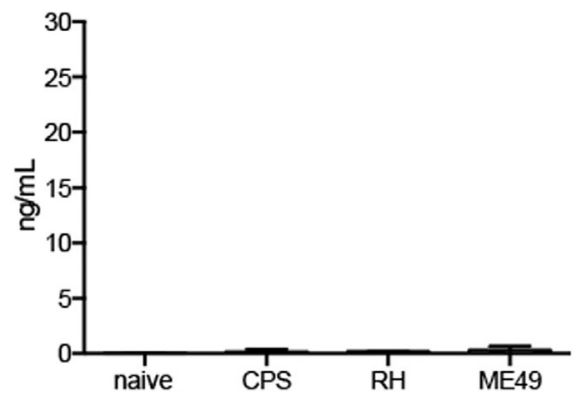

$\mathrm{IL}-1 \beta$

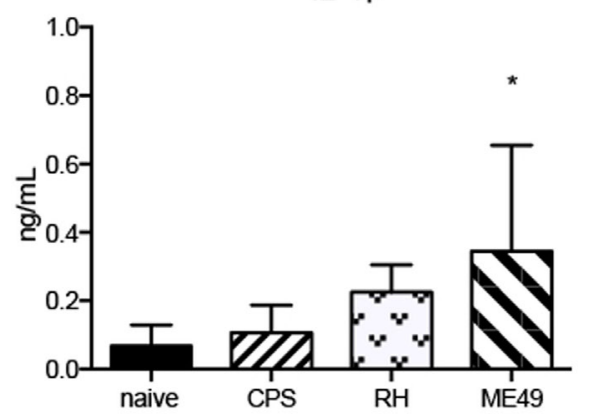

IL-17A
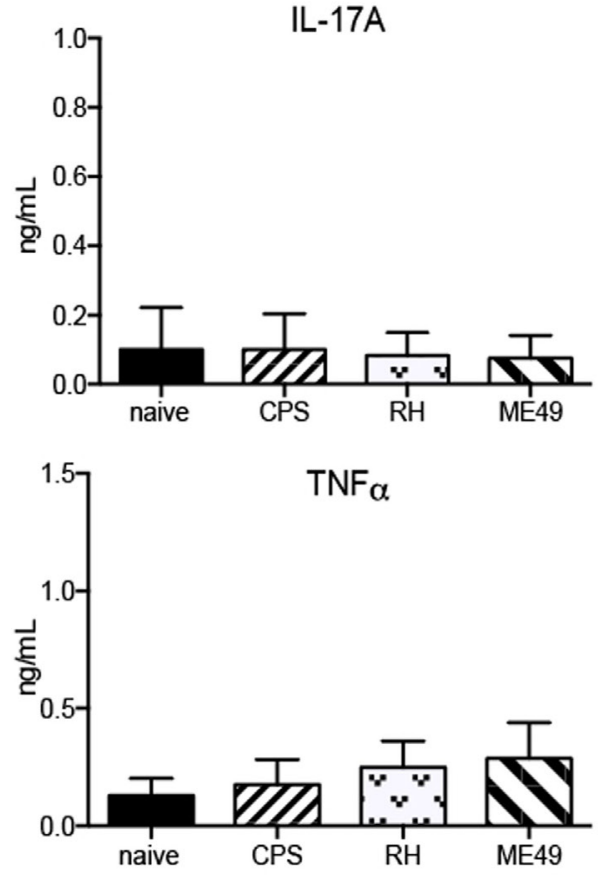

FIGURE 8 | Cytokine levels in mice peritoneum, spleen, and plasma after T. gondii infection. 

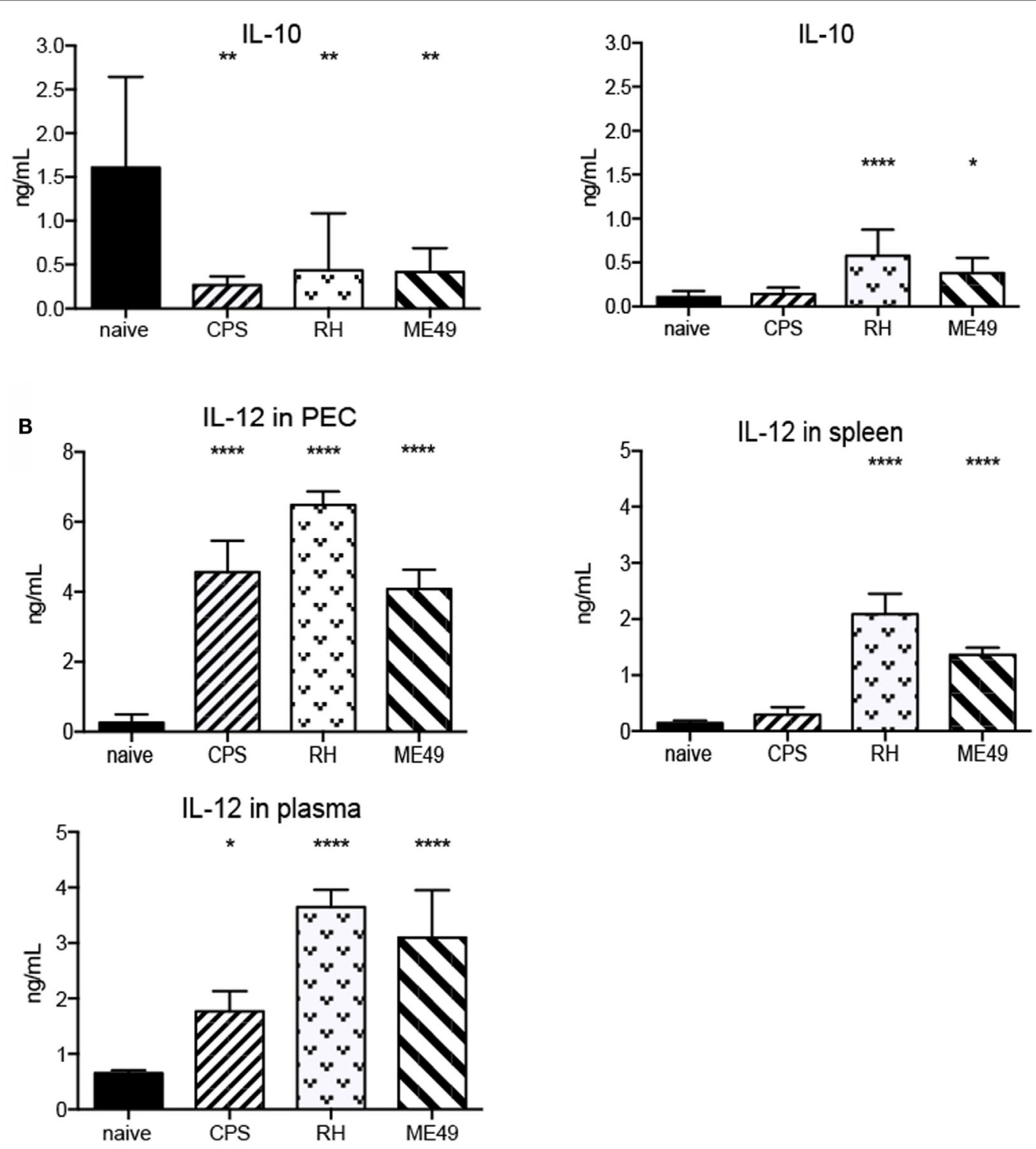

FIGURE 8 | Continued.

Multiplex cytokine analysis was performed with PEC and splenocytes from naive and 5-day-infected animals. PECs and splenocytes were harvested and plated for $24 \mathrm{~h}$. The concentrations of IFN $\gamma$, IL-1 $\beta$, IL-10, TNF $\alpha$, and IL-17A were simultaneously measured by multiplex assay in cultured cell supernatants. (A) Bar graphs present combined data from two separate experiments with an $n=4$ animals per infectious parasite strain per experiment. (B) Bar graphs present combined data from two separate experiments with an $n=4$ animals per infectious parasite strain per experiment. Individual values shown are mean \pm SD. Serum was harvested from naive and infected animals. Supernatant from PEC, splenocytes, and serum were assayed for IL-12p40 by ELISA. Individual values shown are mean \pm SD. Statistical differences are represented by ${ }^{\star} p<0.05,{ }^{\star \star} p<0.01,{ }^{\star \star \star} p<0.001$, and ${ }^{\star \star \star \star} p<0.0001$ in comparison with the control groups (naive).

showed similar IL-12p40 production profiles as the $\mathrm{RH}$ strain. Cps1-1 infection induced increase of the peritoneal and serum, but not splenic IL-12p40 (Figure 8B).

\section{T. gondii Parasite Burden in Mice Peritoneum and Spleen}

Differences observed in cNK cell responses measured in this manuscript could be due to the amount of parasites present in each of the tissues. Although we used common dosages, $1 \times 10^{6}$ cps $1-1,1 \times 10^{3} \mathrm{RH}$ tach., and $10 \mathrm{ME} 49$ cysts, the initial infectious dose was not normalized between strains. Therefore, it is important to measure parasite burdens in each tissue. Parasite numbers were quantified using real-time PCR for parasite-specific B1 gene in PEC and in spleen 5 days after infection. As expected, attenuated cps1-1 parasites that are unable to proliferate in the absence of uracil were found at very low levels in PEC and not detected in spleen (Figure 9). In contrast, higher numbers of $\mathrm{RH}$ 

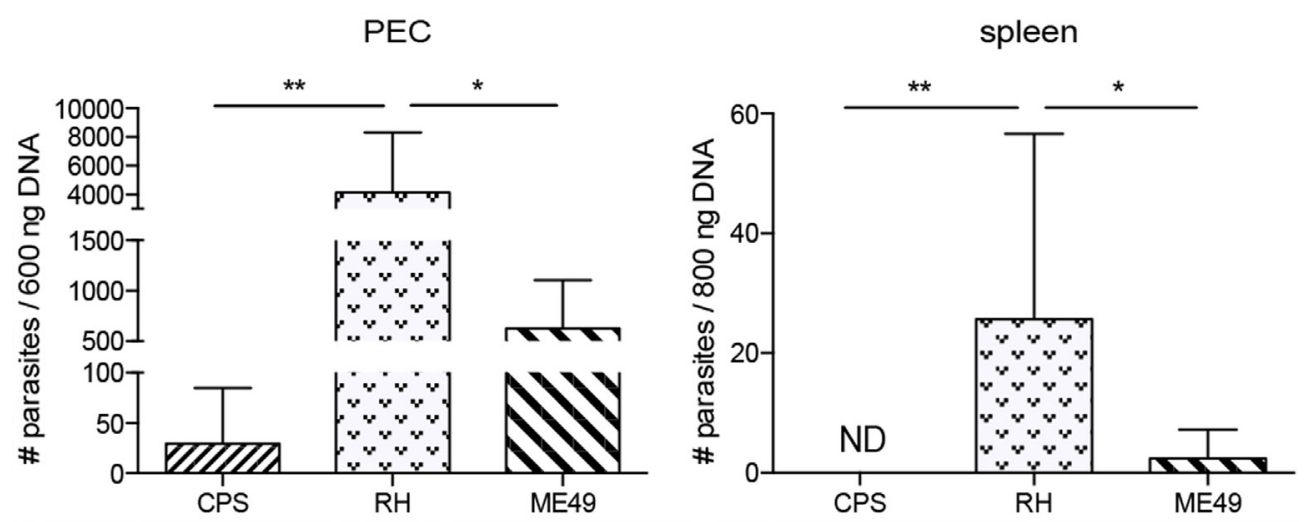

FIGURE 9 | The parasite numbers in mice peritoneum and spleen $\mathbf{5}$ days after $\boldsymbol{T}$. gondii infection. Real-time semi-qPCR was performed to amplify T. gondii-specific B1 gene present in the PECs and spleens harvested from 5-day-T. gondii-infected mice. Parasite equivalents were determined by extrapolation from a standard curve. Bar graphs present combined data from three separate experiments with an $n=4$ animals per infectious parasite strain per experiment. Individual values shown are mean $\pm \mathrm{SD}$

and ME49 parasites were detected in both PEC and spleen. The parasite loads were higher after infection with virulent type I than avirulent type II strain.

\section{DISCUSSION}

Conventional natural killer cells are critical for early immunity to $T$. gondii infection $(5,30)$. How infection with $T$. gondii strains of different virulence affects cNK cell biology and their ability to respond is not known. Here, a comprehensive assessment of cell number, subpopulation composition based on surface receptor expression, function, phenotype of functional cells, maturation, activation, and proliferation of $\mathrm{cNK}$ cells was performed to determine how different $T$. gondii strains impact their response during acute infection. The findings demonstrate $\mathrm{cNK}$ cells were activated and functional at the site of infection (PEC) and in spleen in a graded manner after infection with RH, ME49, and cps 1-1 parasites. cNK cells were not proliferating at day 5 post infection. A dominant responding $\mathrm{cNK}$ cell phenotype based on activating and inhibitory receptor expression was not observed after infection with any of the strains. Maturation of cNK cells after both RH and ME49 infections was also reduced, and immature stages of cNK cells were more pronounced than after cps1-1 infection. KLRG1 expression on cNK cells was induced by all infections with KLRG1 expressed on both mature and immature cNK cells after RH and ME49 infections. In contrast, after cps1-1 infection, only mature CD11b+cNK cells expressed KLRG1. In spleen, the frequency of CD69+ cNK cells was higher on those from RH- and ME49-infected animals compared with cps1-1, which may indicate higher level of activation-induced cell death $(39,44)$ and explain the loss of the mature $\mathrm{cNK}$ cell population in $\mathrm{RH}$ and ME49 infections. In both PEC and spleen, the highest parasite burdens were detected after infection with $\mathrm{RH}$ strain, followed by ME49 strain. Parasites were detected in PEC only and not in spleen after cps1-1 infection. Taken together, the data suggest that, as parasite load increases, $\mathrm{cNK}$ cell responses may be negatively affected giving rise to a defective $\mathrm{cNK}$ cell compartment.

\section{cNK Cell Number after T. gondii Infection}

The presence of T. gondii parasites appears to negatively impact splenic cNK cell counts in a graded manner, after intraperitoneal infection. Whether this is also dependent upon parasite virulence is not clear. We observed decrease in splenic cNK cell frequency and numbers 5 days after both type I RH and type II ME49 in comparison to the cps1-1 infection. Contraction of cNK cells has been shown after $P$. yoelii infection in mice (45), in Plasmodium falciparum-infected patients (46), after MCMV infection (47), and in a Con A-induced hepatitis model (48). This decrease in cNK cell counts could potentially be explained by the migration of splenic $\mathrm{cNK}$ cells to other sites, in particular, to the site of infection. Our observations may support this idea because cNK cells did not proliferate 5 days after the infection in PEC or spleen. cNK cells may proliferate earlier or later in response to $T$. gondii infection. Infection also increased mature KLRG1+ cNK cell numbers adding support for this hypothesis because mature cNK cells are more capable of migration than proliferation (49). Interestingly, i.p. IFN $\gamma$ treatment mobilizes cNK cells from spleen and bone marrow into circulation and promotes cNK cell accumulation, but not proliferation in the peritoneum and tumor metastatic sites (48). Despite this possibility, there was no increase in $\mathrm{cNK}$ cell numbers in peritoneum after i.p. infection with replicating parasites, in contrast to non-replicating cps1-1 strain. Another explanation to the above observation could be the death of cNK cells induced by the infection with virulent parasites. Indeed, depending on the parasite virulence, T. gondii infection triggers activation of the immunoregulatory mechanisms (50-52). One factor involved in immune regulation is $\operatorname{CD} 69(39,44)$. CD69 has been shown to prevent immunopathology caused by Listeria monocytogenes infection (44). Additionally, CD69 deficient animals were better protected against vaccinia virus and had increased cNK 
cell numbers due to the decreased cell death rate (39). Thus, increased CD69+ cNK cells after RH and ME49 infection could be indicative of increased cNK cell apoptosis. In summary, both cNK cell migration and cell death due to inflammation may contribute to the decrease of cNK cell counts in spleen after infection with virulent $T$. gondii strains.

\section{cNK Cell Function}

Different strains of $T$. gondii trigger differing levels of cNK cell activation in PEC and in spleen. cNK cells are a source of IFN $\gamma$ during acute $T$. gondii infection $(8,30)$. cNK cell cytotoxic activity is not well understood and may be reduced in a response to T. gondii infection (10). In the PEC, frequencies of IFN $\gamma+$ and cytotoxic $(\mathrm{CD} 107 \mathrm{a}+)$ cNK cells increased 5 days after infection. This increase was independent on the parasite loads. However, the numbers of IFN $\gamma+$ and CD107a + cNK cells only increased after infection with non-replicating cps 1-1 parasites, but not after infection with replicating $\mathrm{RH}$ and ME49 parasites. $\mathrm{RH}$ and ME49 parasites also triggered increased frequencies, but not numbers, of IFN $\gamma+$ and CD107a + cNK cells in spleen compared with cps1-1 parasites. cNK cell function was activated more locally with cps1-1 strain and is in agreement with previously published studies (53). Whether or not the low numbers of IFN $\gamma+$ and $\mathrm{CD} 107 \mathrm{a}+\mathrm{cNK}$ cells responding to $\mathrm{RH}$ and ME49 infection are sufficient to control infection is not clear. Nevertheless, despite the lower cell frequencies and numbers, $\mathrm{cNK}$ cells from $\mathrm{RH}$ - and ME49-infected mice appeared to produce higher amounts of IFN $\gamma$ on a per cell basis than $\mathrm{cNK}$ cells from cps1-1-infected mice.

The appearance of polyfunctional $(\mathrm{IFN} \gamma+\mathrm{CD} 107 \mathrm{a}+) \mathrm{cNK}$ cells in a response to T. gondii parasites may be advantageous for the resolution of the infection. We observed polyfunctional cNK cells to increase in frequency and numbers in peritoneum 5 days after cps 1-1 infection. RH and ME49 infection elicited reduced cNK cell polyfunction. Polyfunctional cNK cells responses are advantageous during $\operatorname{HIV}(28,29)$. The fact that the highest numbers of bifunctional $\mathrm{cNK}$ cells were found after cps 1-1 infection and the lowest, after RH infection, could potentially correlate with the outcome of these types of infection. Nevertheless, whether polyfunctional cNK cells are superior to the monofunctional cNK cells during $T$. gondii infection needs to be further investigated.

\section{cNK Cell Phenotype}

Conventional natural killer cells can be classified based on germline-encoded activating and inhibitory receptor expression. These receptors recognize stress-induced or pathogen-specific ligands and MHC I molecules, respectively. The distribution of cNK cell subpopulations, based on activating and inhibitory receptor expression, responding to infection is not affected by the T. gondii strain. T. gondii infection stimulated increased frequencies of Ly49H+ and Ly49D+ cNK cells, decreased frequencies of CD94+NKG2A + cNK cells and no change in Ly49I+ cNK cells at the site of infection. The change in frequency of specific cNK cell subsets was not significantly different when compared between three strains. We found that the frequency of $\mathrm{Ly} 49 \mathrm{H}+$ and Ly49D+cNK cells increased at the infection site. In contrast, the expression level of the activating receptor NKG2D decreased after infection. This is supported by a previous study where peritoneal cNK cells also showed decreased NKG2D expression during acute ME49 infection (54). Interestingly, NKG2D has been shown to be involved in the regulation of DCs by cNK cells during T. gondii to promote CD8 $\mathrm{T}$ cell responses (55). Whether different T. gondii strains affect cNK cell help of DCs and CD8 T cell responses will be important to investigate.

Since similar changes in frequencies of activating receptor expressing cNK cells occurred after infection with all three parasite strains, cNK cell responses may be independent of activating ligands for these receptors. cNK cells can expand in two phases: first via cytokines and second via recognition of activating ligands in response to infection giving rise to dominant $\mathrm{cNK}$ cell populations (32). Therefore, we hypothesize that the $\mathrm{cNK}$ cell response to $T$. gondii infection is primarily cytokine-driven rather than ligand-driven, since no specific population appears to increase over others during parasite infection.

Conventional natural killer cells acquire full functional potential via a process called licensing (56). Licensed cNK cells express array of inhibitory receptors, including Ly49I and heterodimeric CD94/NKG2A, that recognize classical MHC I and non-classical MHC I (Qa-1), respectively. Unlicensed cNK cells (those not expressing inhibitory receptors) can dominate acute responses to viral infections (57). Our data show that the frequency of Ly49I+ NK cells did not change at the site of infection; however, the frequency of CD94/NKG2A cNK cell subset decreased after the infection. These data suggest that an unlicensed rather than licensed cNK cell population is responding to T. gondii infection. These changes occurred regardless of parasite strain. One reason inhibitory receptor expressing $\mathrm{cNK}$ cells can change in number is through recognition of MHC Class I (58). Whether T. gondii parasites alter classical and non-classical MHC I expression on cells is not clear $(59,60)$.

Despite cNK cell subset changes after T. gondii infection, all the subsets were almost equally distributed in the IFN $\gamma$-producing $\mathrm{cNK}$ cell population. The changes in numbers of IFN $\gamma$-producing cNK cells expressing activating and inhibitory receptors were reminiscent of the changes in numbers of bulk IFN $\gamma$-producing cNK cells. Thus, there was no dominant cNK cell subset identified by the phenotypic analysis of IFN $\gamma+c N K$ cells. This is different from other infections, including MCMV, HCMV, HIV, Hantavirus, and Chikungunya infections where dominant $\mathrm{cNK}$ cell populations are found (17-23). Since we did not find the dominant $\mathrm{cNK}$ cell population responding to T. gondii infection and all the strains triggered similar changes in distribution of $\mathrm{cNK}$ cell subsets at the site of infection, we hypothesize that $\mathrm{cNK}$ cell response to T. gondii infection is global, cytokine-driven, rather than specific to T. gondii-induced cNK cell activating ligands.

\section{cNK Cell Maturation}

Infection with replicating $T$. gondii parasites negatively impacts cNK cell maturation. Peripheral cNK cell maturation is marked by downregulation of CD27 and upregulation of CD11b and KLRG1. At the infection site, we observed an increase in highly mature CD27-CD11b + cNK cells after infection with ME49 and cps1-1 parasites. In contrast, after RH infection in both sites and 
after ME49 infection in spleen, there were fewer mature cNK cells present. This could be explained by the death of mature cells or/ and altered cNK cell development. The death of mature cNK cells induced by the infection can contribute to the decrease in the mature cNK cell compartment, but does not explain the increase in numbers of immature cNK cells. Therefore, one possible explanation may be that high level inflammation induced by virulent parasites facilitated the premature escape of $\mathrm{cNK}$ cells from the bone marrow, the primary site for $\mathrm{cNK}$ cell development. For example, CCL3 has been shown to overcome CXCL12-induced retention of $\mathrm{CD} 11 \mathrm{~b}^{\text {low }} \mathrm{cNK}$ cells in the bone marrow and recruit these cells to the blood (61). It will be important to address whether increase in immature cNK cells compartment in peritoneum and spleen after the infection with virulent $T$. gondii parasites is due to the altered $\mathrm{cNK}$ cell development in bone marrow. The presence of the incompetent immature CD11b-cNK cells at the expense of mature and functional CD11b+cNK cells after RH and ME49 infections, and the opposite after cps1-1 immunization, could be associated with the outcomes of the infections. We hypothesize that the lack in peripheral mature cNK cells contributes to the susceptibility to T. gondii infection.

\section{Cytokine Milieu, Parasite Burden, and cNK Cell Response}

Cytokines were shown to initiate proliferation of bulk cNK cells followed by selection of a specific $\mathrm{cNK}$ cell population responding to MCMV infection (33). We did not find dominant $\mathrm{cNK}$ cell population by receptor phenotype responding to $T$. gondii infection. cNK cell response to $T$. gondii infection seems to be broad, non-specific and is more likely to be driven by cytokines. cNK cell responses are dependent upon IL-12 after T. gondii infection $(6,42)$. As expected, at the site of infection, the levels of proinflammatory cytokines IL-12, IFN $\gamma$, and IL-17 were increased, and the level of immunoregulatory cytokine IL-10 was decreased, 5 days after infection with three T. gondii strains. In spleen, both IL-12 and IL-10 cytokines were elevated after infection with replicating strains, in contrast to non-replicating cps1-1 strain that did not induce this change. IL-12 concentration was the highest after the infection with highly virulent $\mathrm{RH}$ parasites, followed by moderately virulent ME49 infection, and the lowest IL-12 production was induced by attenuated cps 1-1 infection. This is supported by the fact that, 5 days after infection, RH parasite numbers were more abundant than ME49 and cps1-1 parasites. Proinflammatory cytokine overproduction induced by high parasite numbers after infection with virulent $T$. gondii strains leads to higher mortality rate due to the tissue necrosis-, immunopathology- (50-52, 62), and activation-induced cell death (63). The levels of IL-12 and IFN $\gamma$ could negatively impact the $\mathrm{cNK}$ cell population similar to adaptive immune cell populations as previously shown.

IL-1 $\beta$ production increased after cps $1-1$ infection in PEC. This correlates well with the quality of cNK cell responses at that site compared with RH and ME49. It has been shown that IL- $1 \beta$ boosts IFN $\gamma$ production (64-66) and favors $\mathrm{cNK}$ cell development from their precursors (67). IL-1 $\beta$ is important for IL-12 induction of IFN $\gamma$ production in $\mathrm{cNK}$ cells during $T$. gondii infection (68).
Whether IL-1 $\beta$ can be impacted by parasite virulence needs to be further investigated.

Infection with all parasite strains stimulated increased levels of IL-17 at the site of infection. IL-17 is essential for the control of infection (69), and cNK cells are the relevant source of IL-17 during acute toxoplasmosis (70). The decrease in frequency and numbers of cNK cells in spleen after infection with replicating parasites may also be affected by IL-10 production, since IL-10 is an immunoregulatory cytokine that balances the proinflammatory immune responses that can be detrimental to the host $(52,71)$. In peritoneum, where we observed the most robust cNK cell response, IL-10 was decreased after infection with all the strains. IL-10 was increased in spleen after infection with virulent $\mathrm{RH}$ and ME49 parasites compared with cps1-1 parasites.

\section{CONCLUSION}

In the present study, we, in detail, characterized cNK cell response to T. gondii infection. Infection with Type I RH parasites and Type II ME49 parasites triggers high level of inflammation associated with robust production of IL-12 in PEC, spleen and blood. This may promote reduction in splenic cNK cell compartment. This decrease in number may be due to activation induced cell death and/or migration of cells to the infection site. All three T. gondii strains mediated increase in mono- and polyfunctional $\mathrm{cNK}$ cells at the infection site. Infection with different parasite strains stimulated similar changes in cNK cell subsets expressing activating and inhibitory receptors. Whether the changes in $\mathrm{cNK}$ cell phenotype are associated with the cytokine signaling received and/or the change in the ligand expression is not clear. We found that attenuated T. gondii infection could stimulate an increase in cNK cell maturation. However, infection with replicating parasites reduced mature $\mathrm{cNK}$ cells and increased immature cNK cell output. Thus, many open questions remain about how T. gondii parasites may impact $\mathrm{cNK}$ development and promote early control of infection. Understanding how infection with T. gondii parasites of different virulence impacts $\mathrm{cNK}$ cell response is important for the development of the therapies to prevent and treat T. gondii infection in humans.

\section{AUTHOR CONTRIBUTIONS}

DI designed the study, performed the experiments, analyzed the data, and drafted and revised the manuscript. RF performed the experiments and analyzed the data. JG designed the study and drafted and revised the manuscript. All authors read and approved the final manuscript.

\section{ACKNOWLEDGMENTS}

The authors thank Jacob T. Berg for acquiring multiplex cytokine data on a MAGPIX mulitplex reader.

\section{FUNDING}

This research was supported by University of Wyoming and USDA NIFA. 


\section{REFERENCES}

1. Hill DE, Chirukandoth S, Dubey JP. Biology and epidemiology of Toxoplasma gondii in man and animals. Anim Health Res Rev (2005) 6:41-61. doi:10.1079/ AHR2005100

2. Shwab EK, Zhu XQ, Majumdar D, Pena HF, Gennari SM, Dubey JP, et al. Geographical patterns of Toxoplasma gondii genetic diversity revealed by multilocus PCR-RFLP genotyping. Parasitology (2014) 141:453-61. doi:10.1017/ S0031182013001844

3. Hunter CA, Sibley LD. Modulation of innate immunity by Toxoplasma gondii virulence effectors. Nat Rev Microbiol (2012) 10:766-78. doi:10.1038/ nrmicro2858

4. Suzuki Y, Orellana MA, Schreiber RD, Remington JS. Interferon-gamma: the major mediator of resistance against Toxoplasma gondii. Science (1988) 240:516-8. doi:10.1126/science.3128869

5. Sher A, Oswald IP, Hieny S, Gazzinelli RT. Toxoplasma gondii induces a T-independent IFN-gamma response in natural killer cells that requires both adherent accessory cells and tumor necrosis factor-alpha. J Immunol (1993) 150:3982-9.

6. Gazzinelli RT, Hieny S, Wynn TA, Wolf S, Sher A. Interleukin 12 is required for the T-lymphocyte-independent induction of interferon gamma by an intracellular parasite and induces resistance in T-cell-deficient hosts. Proc Natl Acad Sci U S A (1993) 90:6115-9. doi:10.1073/pnas.90.13.6115

7. Combe CL, Curiel TJ, Moretto MM, Khan IA. NK cells help to induce CD8(+)-T-cell immunity against Toxoplasma gondii in the absence of CD4(+) T cells. Infect Immun (2005) 73:4913-21. doi:10.1128/IAI.73.8.49134921.2005

8. Goldszmid RS, Caspar P, Rivollier A, White S, Dzutsev A, Hieny S, et al. NK cell-derived interferon-gamma orchestrates cellular dynamics and the differentiation of monocytes into dendritic cells at the site of infection. Immunity (2012) 36:1047-59. doi:10.1016/j.immuni.2012.03.026

9. Hauser WE Jr, Sharma SD, Remington JS. Augmentation of NK cell activity by soluble and particulate fractions of Toxoplasma gondii. J Immunol (1983) 131:458-63.

10. Kamiyama T, Hagiwara T. Augmented followed by suppressed levels of natural cell-mediated cytotoxicity in mice infected with Toxoplasma gondii. Infect Immun (1982) 36:628-36.

11. Sharma SD, Verhoef J, Remington JS. Enhancement of human natural killer cell activity by subcellular components of Toxoplasma gondii. Cell Immunol (1984) 86:317-26. doi:10.1016/0008-8749(84)90386-1

12. Denkers EY, Yap G, Scharton-Kersten T, Charest H, Butcher BA, Caspar P, et al. Perforin-mediated cytolysis plays a limited role in host resistance to Toxoplasma gondii. J Immunol (1997) 159:1903-8.

13. Spits H, Artis D, Colonna M, Diefenbach A, DI Santo JP, Eberl G, et al. Innate lymphoid cells - a proposal for uniform nomenclature. Nat Rev Immunol (2013) 13:145-9. doi:10.1038/nri3365

14. Lanier LL. NK cell recognition. Annu Rev Immunol (2005) 23:225-74. doi:10.1146/annurev.immunol.23.021704.115526

15. Daeron M, Jaeger S, DU Pasquier L, Vivier E. Immunoreceptor tyrosine-based inhibition motifs: a quest in the past and future. Immunol Rev (2008) 224:11-43. doi:10.1111/j.1600-065X.2008.00666.x

16. Biassoni R. Natural killer cell receptors. Adv Exp Med Biol (2008) 640:35-52. doi:10.1007/978-0-387-09789-3_4

17. Sun JC, Beilke JN, Lanier LL. Adaptive immune features of natural killer cells. Nature (2009) 457:557-61. doi:10.1038/nature07665

18. Rolle A, Brodin P. Immune adaptation to environmental influence: the case of NK cells and HCMV. Trends Immunol (2016) 37:233-43. doi:10.1016/j. it.2016.01.005

19. Brunetta E, Fogli M, Varchetta S, Bozzo L, Hudspeth KL, Marcenaro E, et al. Chronic HIV-1 viremia reverses NKG2A/NKG2C ratio on natural killer cells in patients with human cytomegalovirus co-infection. AIDS (2010) 24:27-34. doi:10.1097/QAD.0b013e3283328d1f

20. Gregson JN, Kuri-Cervantes L, Mela CM, Gazzard BG, Bower M, Goodier MR. Short communication: NKG2C+ NK cells contribute to increases in CD16+CD56- cells in HIV type 1+ individuals with high plasma viral load. AIDS Res Hum Retroviruses (2013) 29:84-8. doi:10.1089/AID.2011.0397

21. Guma M, Cabrera C, Erkizia I, Bofill M, Clotet B, Ruiz L, et al. Human cytomegalovirus infection is associated with increased proportions of NK cells that express the CD94/NKG2C receptor in aviremic HIV-1-positive patients. J Infect Dis (2006) 194:38-41. doi:10.1086/504719

22. Bjorkstrom NK, Lindgren T, Stoltz M, Fauriat C, Braun M, Evander M, et al. Rapid expansion and long-term persistence of elevated NK cell numbers in humans infected with hantavirus. J Exp Med (2011) 208:13-21. doi:10.1084/ jem. 20100762

23. Petitdemange $\mathrm{C}$, Becquart $\mathrm{P}$, Wauquier N, Beziat V, Debre P, Leroy EM, et al. Unconventional repertoire profile is imprinted during acute chikungunya infection for natural killer cells polarization toward cytotoxicity. PLoS Pathog (2011) 7:e1002268. doi:10.1371/journal.ppat.1002268

24. Hayakawa Y, Smyth MJ. CD27 dissects mature NK cells into two subsets with distinct responsiveness and migratory capacity. JImmunol (2006) 176:1517-24. doi:10.4049/jimmunol.176.3.1517

25. Chiossone L, Chaix J, Fuseri N, Roth C, Vivier E, Walzer T. Maturation of mouse NK cells is a 4-stage developmental program. Blood (2009) 113:548896. doi:10.1182/blood-2008-10-187179

26. Fogel LA, Sun MM, Geurs TL, Carayannopoulos LN, French AR. Markers of nonselective and specific NK cell activation. J Immunol (2013) 190:6269-76. doi:10.4049/jimmunol.1202533

27. Vivier E, Tomasello E, Baratin M, Walzer T, Ugolini S. Functions of natural killer cells. Nat Immunol (2008) 9:503-10. doi:10.1038/ni1582

28. Kamya P, Boulet S, Tsoukas CM, Routy JP, Thomas R, Cote P, et al. Receptorligand requirements for increased NK cell polyfunctional potential in slow progressors infected with HIV-1 coexpressing KIR3DL1*h/ $/{ }^{*} \mathrm{y}$ and HLA-B ${ }^{\star} 57$. J Virol (2011) 85:5949-60. doi:10.1128/JVI.02652-10

29. Ahmad F, Hong HS, Jackel M, Jablonka A, Lu IN, Bhatnagar N, et al. High frequencies of polyfunctional CD8+ NK cells in chronic HIV-1 infection are associated with slower disease progression. J Virol (2014) 88:12397-408. doi:10.1128/JVI.01420-14

30. Denkers EY, Gazzinelli RT, Martin D, Sher A. Emergence of NK1.1+ cells as effectors of IFN-gamma dependent immunity to Toxoplasma gondii in MHC class I-deficient mice. J Exp Med (1993) 178:1465-72. doi:10.1084/ jem.178.5.1465

31. Alter G, Malenfant JM, Altfeld M. CD107a as a functional marker for the identification of natural killer cell activity. J Immunol Methods (2004) 294:15-22. doi:10.1016/j.jim.2004.08.008

32. Dokun AO, Kim S, Smith HR, Kang HS, Chu DT, Yokoyama WM. Specific and nonspecific NK cell activation during virus infection. Nat Immunol (2001) 2:951-6. doi:10.1038/ni714

33. Beaulieu AM, Zawislak CL, Nakayama T, Sun JC. The transcription factor Zbtb32 controls the proliferative burst of virus-specific natural killer cells responding to infection. Nat Immunol (2014) 15:546-53. doi:10.1038/ ni. 2876

34. Arase H, Mocarski ES, Campbell AE, Hill AB, Lanier LL. Direct recognition of cytomegalovirus by activating and inhibitory NK cell receptors. Science (2002) 296:1323-6. doi:10.1126/science.1070884

35. Huntington ND, Tabarias H, Fairfax K, Brady J, Hayakawa Y, Degli-Esposti $\mathrm{MA}$, et al. NK cell maturation and peripheral homeostasis is associated with KLRG1 up-regulation. JImmunol (2007) 178:4764-70. doi:10.4049/ jimmunol.178.8.4764

36. Walzer T, Chiossone L, Chaix J, Calver A, Carozzo C, Garrigue-Antar L, et al. Natural killer cell trafficking in vivo requires a dedicated sphingosine 1-phosphate receptor. Nat Immunol (2007) 8:1337-44. doi:10.1038/ ni1523

37. Jenne CN, Enders A, Rivera R, Watson SR, Bankovich AJ, Pereira JP, et al. T-bet-dependent S1P5 expression in NK cells promotes egress from lymph nodes and bone marrow. JExp Med (2009) 206:2469-81. doi:10.1084/ jem. 20090525

38. Esplugues E, Sancho D, Vega-Ramos J, Martinez C, Syrbe U, Hamann A, et al. Enhanced antitumor immunity in mice deficient in CD69. J Exp Med (2003) 197:1093-106. doi:10.1084/jem.20021337

39. Notario L, Alari-Pahissa E, DE Molina A, Lauzurica P. CD69 deficiency enhances the host response to vaccinia virus infection through altered NK cell homeostasis. J Virol (2016) 90(14):6464-74. doi:10.1128/JVI.00550-16

40. Miguel-Garcia A, Matutes E, Tarin F, Garcia-Talavera J, Miguel-Sosa A, Carbonell F, et al. Circulating Ki67 positive lymphocytes in multiple myeloma and benign monoclonal gammopathy. JClin Pathol (1995) 48:835-9. doi: $10.1136 /$ jcp.48.9.835 
41. Lopez F, Belloc F, Lacombe F, Dumain P, Reiffers J, Bernard P, et al. Modalities of synthesis of Ki67 antigen during the stimulation of lymphocytes. Cytometry (1991) 12:42-9. doi:10.1002/cyto.990120107

42. Hunter CA, Subauste CS, Van Cleave VH, Remington JS. Production of gamma interferon by natural killer cells from Toxoplasma gondii-infected SCID mice: regulation by interleukin-10, interleukin-12, and tumor necrosis factor alpha. Infect Immun (1994) 62:2818-24.

43. Tighe PJ, Ryder RR, Todd I, Fairclough LC. ELISA in the multiplex era: potentials and pitfalls. Proteomics Clin Appl (2015) 9:406-22. doi:10.1002/ prca.201400130

44. Vega-Ramos J, ALARI-Pahissa E, Valle JD, Carrasco-Marin E, Esplugues E, Borras M, et al. CD69 limits early inflammatory diseases associated with immune response to Listeria monocytogenes infection. Immunol Cell Biol (2010) 88:707-15. doi:10.1038/icb.2010.62

45. Roland J, Soulard V, Sellier C, Drapier AM, DI Santo JP, Cazenave PA, et al. NK cell responses to Plasmodium infection and control of intrahepatic parasite development. JImmunol (2006) 177:1229-39. doi:10.4049/ jimmunol.177.2.1229

46. Orago AS, Facer CA. Cytotoxicity of human natural killer (NK) cell subsets for Plasmodium falciparum erythrocytic schizonts: stimulation by cytokines and inhibition by neomycin. Clin Exp Immunol (1991) 86:22-9. doi:10.1111/ j.1365-2249.1991.tb05768.x

47. Robbins SH, Tessmer MS, Mikayama T, Brossay L. Expansion and contraction of the NK cell compartment in response to murine cytomegalovirus infection. J Immunol (2004) 173:259-66. doi:10.4049/jimmunol.173.1.259

48. Wald O, Weiss ID, Wald H, Shoham H, Bar-Shavit Y, Beider K, et al. IFN-gamma acts on T cells to induce NK cell mobilization and accumulation in target organs. J Immunol (2006) 176:4716-29. doi:10.4049/jimmunol. 176.8.4716

49. Hayakawa Y, Huntington ND, Nutt SL, Smyth MJ. Functional subsets of mouse natural killer cells. Immunol Rev (2006) 214:47-55. doi:10.1111/ j.1600-065X.2006.00454.x

50. Gazzinelli RT, Wysocka M, Hieny S, Scharton-Kersten T, Cheever A, Kuhn R, et al. In the absence of endogenous IL-10, mice acutely infected with Toxoplasma gondii succumb to a lethal immune response dependent on CD4+ $\mathrm{T}$ cells and accompanied by overproduction of IL-12, IFN-gamma and TNFalpha. J Immunol (1996) 157:798-805.

51. Neyer LE, Grunig G, Fort M, Remington JS, Rennick D, Hunter CA. Role of interleukin-10 in regulation of T-cell-dependent and T-cell-independent mechanisms of resistance to Toxoplasma gondii. Infect Immun (1997) 65:1675-82.

52. Suzuki Y, Sher A, Yap G, Park D, Neyer LE, Liesenfeld O, et al. IL-10 is required for prevention of necrosis in the small intestine and mortality in both genetically resistant $\mathrm{BALB} / \mathrm{c}$ and susceptible C57BL/6 mice following peroral infection with Toxoplasma gondii. JImmunol (2000) 164:5375-82. doi:10.4049/jimmunol.164.10.5375

53. Gigley JP, Fox BA, Bzik DJ. Cell-mediated immunity to Toxoplasma gondii develops primarily by local Th1 host immune responses in the absence of parasite replication. JImmunol (2009) 182:1069-78. doi:10.4049/ jimmunol.182.2.1069

54. Goldszmid RS, Bafica A, Jankovic D, Feng CG, Caspar P, Winkler-Pickett R, et al. TAP-1 indirectly regulates CD4+ T cell priming in Toxoplasma gondii infection by controlling NK cell IFN-gamma production. J Exp Med (2007) 204:2591-602. doi:10.1084/jem.20070634

55. Guan H, Moretto M, Bzik DJ, Gigley J, Khan IA. NK cells enhance dendritic cell response against parasite antigens via NKG2D pathway. J Immunol (2007) 179:590-6. doi:10.4049/jimmunol.179.1.590

56. Kim S, Poursine-Laurent J, Truscott SM, Lybarger L, Song YJ, Yang L, et al. Licensing of natural killer cells by host major histocompatibility complex class I molecules. Nature (2005) 436:709-13. doi:10.1038/nature03847

57. Orr MT, Murphy WJ, Lanier LL. 'Unlicensed' natural killer cells dominate the response to cytomegalovirus infection. Nat Immunol (2010) 11:321-7. doi:10.1038/ni.1849
58. Kadri N, Thanh TL, Hoglund P. Selection, tuning, and adaptation in mouse NK cell education. Immunol Rev (2015) 267:167-77. doi:10.1111/imr.12330

59. Debierre-Grockiego F, Molitor N, Schwarz RT, Luder CG. Toxoplasma gondii glycosylphosphatidylinositols up-regulate major histocompatibility complex (MHC) molecule expression on primary murine macrophages. Innate Immun (2009) 15:25-32. doi:10.1177/1753425908099936

60. Luder CG, Lang T, Beuerle B, Gross U. Down-regulation of MHC class II molecules and inability to up-regulate class I molecules in murine macrophages after infection with Toxoplasma gondii. Clin Exp Immunol (1998) 112:308-16. doi:10.1046/j.1365-2249.1998.00594.x

61. Bernardini G, Sciume G, Bosisio D, Morrone S, Sozzani S, Santoni A. CCL3 and CXCL12 regulate trafficking of mouse bone marrow NK cell subsets. Blood (2008) 111:3626-34. doi:10.1182/blood-2007-08-106203

62. Nguyen TD, Bigaignon G, Markine-Goriaynoff D, Heremans H, Nguyen TN, Warnier G, et al. Virulent Toxoplasma gondii strain RH promotes T-cellindependent overproduction of proinflammatory cytokines IL12 and gammainterferon. J Med Microbiol (2003) 52:869-76. doi:10.1099/jmm.0.04860-0

63. Begum-Haque S, Haque A, Kasper LH. Apoptosis in Toxoplasma gondii activated $\mathrm{T}$ cells: the role of IFNgamma in enhanced alteration of Bcl-2 expression and mitochondrial membrane potential. Microb Pathog (2009) 47:281-8. doi:10.1016/j.micpath.2009.09.004

64. Hughes T, Becknell B, Freud AG, Mcclory S, Briercheck E, Yu J, et al. Interleukin-1beta selectively expands and sustains interleukin-22+ immature human natural killer cells in secondary lymphoid tissue. Immunity (2010) 32:803-14. doi:10.1016/j.immuni.2010.06.007

65. Cooper MA, Fehniger TA, Ponnappan A, Mehta V, Wewers MD, Caligiuri MA. Interleukin-1beta costimulates interferon-gamma production by human natural killer cells. Eur J Immunol (2001) 31:792-801. doi:10.1002/1521-4141(200103)31:3<792::AID-IMMU792>3.0.CO;2-U

66. van de Wetering D, DE Paus RA, van Dissel JT, van de Vosse E. Salmonella induced IL-23 and IL-1beta allow for IL-12 production by monocytes and Mphil through induction of IFN-gamma in CD56 NK/NK-like T cells. PLoS One (2009) 4:e8396. doi:10.1371/journal.pone.0008396

67. Ambrosini P, Loiacono F, Conte R, Moretta L, Vitale C, Mingari MC. IL-1beta inhibits ILC3 while favoring NK-cell maturation of umbilical cord blood CD34(+) precursors. Eur J Immunol (2015) 45:2061-71. doi:10.1002/ eji.201445326

68. Hunter CA, Chizzonite R, Remington JS. IL-1 beta is required for IL-12 to induce production of IFN-gamma by NK cells. A role for IL-1 beta in the $\mathrm{T}$ cell-independent mechanism of resistance against intracellular pathogens. J Immunol (1995) 155:4347-54.

69. Kelly MN, Kolls JK, Happel K, Schwartzman JD, Schwarzenberger P, Combe C, et al. Interleukin-17/interleukin-17 receptor-mediated signaling is important for generation of an optimal polymorphonuclear response against Toxoplasma gondii infection. Infect Immun (2005) 73:617-21. doi:10.1128/ IAI.73.1.617-621.2005

70. Hunter CA. New IL-12-family members: IL-23 and IL-27, cytokines with divergent functions. Nat Rev Immunol (2005) 5:521-31. doi:10.1038/nri1648

71. Jankovic D, Kullberg MC, Feng CG, Goldszmid RS, Collazo CM, Wilson M, et al. Conventional T-bet(+)Foxp3(-) Th1 cells are the major source of host-protective regulatory IL-10 during intracellular protozoan infection. J Exp Med (2007) 204:273-83. doi:10.1084/jem.20062175

Conflict of Interest Statement: The authors declare that the research was conducted in the absence of any commercial or financial relationships that could be construed as a potential conflict of interest.

Copyright (๑) 2016 Ivanova, Fatima and Gigley. This is an open-access article distributed under the terms of the Creative Commons Attribution License (CC BY). The use, distribution or reproduction in other forums is permitted, provided the original author(s) or licensor are credited and that the original publication in this journal is cited, in accordance with accepted academic practice. No use, distribution or reproduction is permitted which does not comply with these terms. 